\title{
Why are Firms that Export Cleaner? International Trade, Abatement and Environmental Emissions
}

\author{
Revised version of CEPR Discussion paper no. 8583.
}

\begin{abstract}
This paper proposes a detailed mechanism for why exporting firms may have a lower emission intensity when emissions are subject to an environmental tax. This mechanism of our model is supported by Swedish firm-level data. Our mechanism runs through firms' endogenous investments in abatement. Firms' abatement investments depend on their production volumes, since a larger scale allows them to spread the fixed costs of abatement investment across more units. Production volumes increase in firm productivity and, as a consequence, firms' emission intensity is negatively related to firm productivity. Exporting also leads to higher production volumes and thereby to a lower emission intensity. Thus, trade has an effect on emissions independently of firm productivity. Trade therefore leads to higher but cleaner production. The overall effect of trade on emissions is neutral in our model. Trade liberalization does not affect aggregate emissions in our benchmark case of symmetric countries.
\end{abstract}

JEL Classification: F12, F14, F18, Q56

Keywords:heterogeneous firms, environmental emissions, abatement, international trade 


\section{Introduction}

There is no consensus on the effect of international trade on the environment, in particular on the effect of trade on global emissions. Neither the theoretical nor the empirical literature provides a clean cut answer to the link between trade and environmental emissions. International trade has opposing effects in neoclassical models. On the one hand, trade increases income, which will tend to increase the demand for a clean environment and therefore increase investments in clean technology and abatement. On the other hand, trade liberalization may also imply an overall expansion of dirty production, because trade allows countries with low emission standards to become pollution havens. Copeland and Taylor (1995) show how trade liberalization may increase global emissions if the income differences between the liberalizing countries are large, as dirty industries are likely to expand strongly in the poor country with low environmental standards. Hence, we do not know if international trade increases or decreases the emissions of greenhouse gases and contributes to global warming. However, this paper sets out to explain why we may expect exporters to emit less, and why trade liberalization may thus lead to a cleaner industrial production. This is done by focusing on inter-firm productivity differentials and interdependence among productivity, exporting, abatement and environmental emissions.

The empirical literature that analyzes the link between trade in goods and emissions based on sector-level data and Heckscher Ohlin type models is also inconclusive. ${ }^{1}$ Antweiler et al. (2001) and Frankel and Rose (2005) find that trade decreases emissions. Using sectorlevel data for the U.S., Ederington et al. (2004) do not find any evidence that pollution intensive industries have been disproportionately affected by tariff changes. On the other hand, also using sector-level trade data, Levinson and Taylor (2008) find evidence that higher environmental standards in the US have increased the imports from Mexico in dirty industries.

This paper proposes a detailed mechanism for why exporting firms, which are subject to an environmental tax, may have a lower emission intensity. Our point of departure is the Melitz (2003) model with heterogeneous firms and intra-industry trade. Our mechanism runs through firms' endogenous investments in abatement. Firms' abatement investments depend on their production volumes, as a larger scale allows them to spread the fixed costs of abatement investment across more units. Production volumes increase in firm productivity and, as a consequence, firms' emission intensity is negatively related to firm productivity.

\footnotetext{
${ }^{1}$ See early surveys by Copeland and Taylor (2004) and Brunnermeier and Levinson (2004).
} 
Exporting also leads to higher production volumes and thereby to a lower emission intensity. Thus, trade has an effect on emissions independently of firm productivity. Our model also predicts that abatement as well as abatement intensity (abatement per output) increase in trade. These properties of the model are supported by Swedish firm-level data.

Our theoretical model also allows for predictions of the impact of trade liberalization on aggregate environmental emissions. Trade affects the exporting and non-exporting sector in different ways. For any level of trade costs, exporters are always cleaner than non-exporters, and we show that trade liberalization makes exporters even cleaner by inducing them to invest more in abatement. But trade liberalization also implies higher production volumes for exporters, which ceteris paribus entails higher emissions. Therefore, there is an increase in total emissions from the exporting sector. However, trade also increases local competition, which implies that the least productive, which are also the dirtiest, firms are forced to close down, while the remaining non-exporters are forced to scale down their production volume. Together, these different effects of trade liberalization serve to decrease total emissions from the non-exporting sector. In our benchmark case of symmetric countries, these effects cancel out, and the overall effect of trade liberalization on emisssions is neutral. That is, aggregate emissions are not affected by trade liberalization. This result is shown to hold in numerical simulations also when the countries are of different size but otherwise symmetric.

We also numerically simulate a case where countries have different emission taxes. Firms are drawn to the low tax economy when trade is liberalized, as predicted by the pollution haven hypothesis, but the low tax economy is also an attractive platform for exporting and firms invest in abatement as they become exporters. We find that the increased abatement investments can be strong enough to decrease global emissions. Thus, we have an antipollution haven case. This is not the only possible outcome, but it is interesting that trade liberalization can lead to lower global emissions under these circumstances, and it may be one of the mechanisms that make it hard to establish an empirical relationship between trade and emissions.

Our theory is related to the idea presented in Levinson (2009) that trade may contribute to reduced pollution since trade liberalization encourages technological upgrading. From a more methodological point of view, our work is also related to the literature on heterogeneous firms and trade induced technological upgrading, see e.g. Bas (2012) and Bustos (2012). Our model is also related to a couple of papers that analyze how firms in a closed economy invest in abatement technology to reduce pollution. Naturally, these do not analyze the relationship between trade and emissions, which is our main interest. Anouliès (2017) analyzes the effects of different policy designs of a cap-and-trade program in a closed economy Melitz model with abatement. Tang et al. (2014) examine the impact of environmental policy within a 
framework of heterogeneous firms in a closed economy. They find that environmental policy reduces both consumption and pollution emission, but that output could be maintained using subsidies directed towards the more productive firms. Cao et al. (2016) analyze a closed economy using a version of the Melitz Ottaviano (2008) model of heterogeneous firms. As in our paper, firms invest in abatement technology to reduce pollution. Their main finding is that there is a hump-shaped relationship between productivity and abatement investments. Our model does instead produce a positive association between productivity and abatement investments and a negative relationship between productivity and abatement intensity (abatement/output), which is consistent with Swedish data.

Finally, a number of papers analyze the relationship between firm-level emissions and trade. Cui et al. (2012) present a theory on trade and emissions and analyze the relationship between exporting and emissions. However, their theoretical model is distinctly different from ours. In our model, exporters' relatively lower emission intensity is due to their endogenous choice of abatement investment, while in their model it is due to exporters' discrete choice of technology of production. Batrakova and Davies (2012) examine the link between exporting and energy use employing Irish manufacturing data. Their theoretical model predicts a positive correlation between exporting and energy expenditures for low energy intensity firms and a smaller or even negative correlation for high energy intensity firms. This asymmetry is due to the fact that trade as such requires extra energy but, on the other hand, may also encourage a shift towards more energy efficient technologies if a firm is highly energy intensive. Their theoretical results are confirmed empirically. Girma et al. (2008) study the reported environmental effects of UK firms' innovations and the role of exporting, and find that exporters are more likely to denote their innovations as having high environmental effects. Kreickemeier and Richter (2014) analyze the effect of trade liberalization on aggregate emissions in a heterogeneous firms model of the Melitz (2003) variety. Their model imposes that firm-level emissions decrease in firm-level productivity with a constant elasticity of emissions w.r.t. productivity. The effect of trade liberalization on aggregate emissions hinges on this elasticity, and aggregate emissions may decrease if the elasticity is high enough. Our paper instead models firm-level emissions as the outcome of endogenous firm-level investments in abatement, and our most central results concern the effect of trade on firm-level emissions and abatement investments. In our framework, trade has an independent effect on firm-level abatement investments, and thereby on emissions. We also find supportive evidence of this using Swedish firm-level data.

The structure of the paper is as follows. The next section presents descriptive evidence on emission intensity, abatement and abatement intensity among non-exporters and exporters relying on data for Swedish manufacturing firms. Motivated by the descriptive evidence, 
Section 3 develops a theoretical model on international trade, environmental emissions and heterogeneous firms. Based on this model, we are able to derive a set of propositions and empirical implications regarding emissions, abatement and trade that are in line with the descriptive evidence. Finally, Section 4 concludes the paper.

\section{Descriptive evidence on $\mathrm{CO} 2$ emissions}

Our model has the property that more productive firms are cleaner since they find it profitable to make larger fixed investments in clean technology. Second, the model shows that exporters are cleaner for a given productivity level, since exporting implies a larger scale of production which motivates a larger fixed investment in clean technology. In this section, we illustrate that these properties of the model are largely consistent with Swedish manufacturing census data. This data contains information at the firm level for a large number of variables. Firms' productivity is measured by total factor productivity, and is calculated from estimates of productivity functions using the method by Levinsohn and Petrin (2003). ${ }^{2}$ Statistics Sweden also collects information on the usage of energy from all manufacturing plants with 10 or more employees, and we have access to these for the time period 2004-2011. The energy statistics include all types of fuel use, from which CO2 emissions (kg) can be calculated by using fuel-specific CO2 emission coefficients provided by Statistics Sweden. CO2 emissions are accurately calculated from fuel inputs since a technology for capturing CO2 at the pipe is not yet operational. ${ }^{3}$ The calculated plant-level emissions are aggregated to the firm level, which we match with the census data. This gives over 3000 observations each year. ${ }^{4}$ We also have access to firm-level data on abatement over the same period. The abatement data is collected based on an annual survey where firms are asked about abatement investments (tSEK) for different purposes including clean air, which we use. Firms are asked to report any investment in machines and equipment specifically aimed at reducing emissions, but also to report expenses related to investment in cleaner machines and technology. In the latter case, they are specifically asked to report the extra expenses related to the choice of investing in cleaner relative to less clean machines and technology. The abatement

\footnotetext{
${ }^{2}$ Production functions are estimated at the two-digit sector level, where we use value added as the measure of firm output. Explanatory variables are labor (measured by the wage bill) and capital. Finally we use raw materials as proxy for contemporaneous productivity shocks. All variables are in logs.

${ }^{3} \mathrm{~A}$ few large power plants are experimenting with capturing $\mathrm{CO} 2$ below ground, but as we are focusing on manufacturing, these are not included in our data.

${ }^{4}$ Note that as the census provides data for all firms, limiting the number to firms with at least one employee, we start with a number of 37745 firms for the period 2004-2011. However, due to the fact that energy statistics are only collected for plants with 10 or more employees, this reduces our sample by close to 30 percent.
} 
data is based on a semi-random sample of manufacturing firms, and includes all manufacturing firms with more than 250 employees, 50 percent of the firms with 100-249 employees, and 20 percent of the firms with 50-99 employees. In total, around 1500 manufacturing firms are surveyed over the time period 2004-2011. Dropping missing observations, we end up with around 600 firms each year.

Table 1 shows how firm-level CO2 emissions per output vary with productivity and with being an exporter. To account for sectorial variations in emissions, we include industry dummies based on five-digit industries, while year dummies pick up time trends. Finally, we also include a firm-level fixed effect. We report regression results where errors are clustered at the firm level, while noting that clustering at the sector level gives very similar results. Columns (1) to (4) in the table show that more productive firms are cleaner (have lower CO2 emissions per output), and that exporters are cleaner also after controlling for productivity, which is an important property of our model. The export dummy has the expected sign but is insignificant in column (5), where firm fixed effects are used. This regression identifies the effect of the export dummy solely on firms that change export status, which is about 25 percent of the firms in our sample. We here have the problem that many of these small firms change back and forth between exporting and not over the sample period, which may explain the low significance in this case.

Table 1: CO2 emissions per output

\begin{tabular}{|c|c|c|c|c|c|}
\hline \multicolumn{6}{|c|}{ Dependent var: $\log (\mathrm{CO} 2$ emissions/output) } \\
\hline & $(1)$ & $(2)$ & $(3)$ & $(4)$ & $(5)$ \\
\hline Export dummy & $\begin{array}{l}-0.317^{* * *} \\
(0.045)\end{array}$ & $\begin{array}{c}-0.251^{* * *} \\
(0.045)\end{array}$ & $\begin{array}{c}-0.121^{* * *} \\
(0.039)\end{array}$ & $\begin{array}{c}-0.133^{* * *} \\
(0.039)\end{array}$ & $\begin{array}{l}-0.010 \\
(0.026)\end{array}$ \\
\hline $\log ($ productivity) & & $\begin{array}{c}-0.162^{* * *} \\
(0.032)\end{array}$ & $\begin{array}{c}-0.418^{* * *} \\
(0.034)\end{array}$ & $\begin{array}{c}-0.416^{* * *} \\
(0.035)\end{array}$ & $\begin{array}{c}-0.222^{* * *} \\
(0.026)\end{array}$ \\
\hline Sector fixed effects (5-digits) & & & $\checkmark$ & $\checkmark$ & $\checkmark$ \\
\hline Year fixed effects & & & & $\checkmark$ & $\checkmark$ \\
\hline Firm fixed effects & & & & & $\checkmark$ \\
\hline Number obs. & 27224 & 27224 & 27224 & 27224 & 27224 \\
\hline
\end{tabular}


Table 2: Abatement

Dependent var: log (Investments in cleaner technology (air))

\begin{tabular}{lccccc} 
& $(1)$ & $(2)$ & $(3)$ & $(4)$ & $(5)$ \\
\hline Export dummy & $0.519^{* * *}$ & $0.496^{* * *}$ & $0.297^{* * *}$ & $0.261^{* *}$ & $0.700^{* *}$ \\
& $(0.0875)$ & $(0.0885)$ & $(0.112)$ & $(0.114)$ & $(0.351)$ \\
Log(productivity) & & & & & \\
& & 0.0442 & $0.610^{* * *}$ & $0.612^{* * *}$ & -0.0496 \\
& & $(0.0273)$ & $(0.0623)$ & $(0.0616)$ & $(0.0979)$
\end{tabular}

Sector fixed effects (2-digits)

Year fixed effects

Firm fixed effects

Number obs.

4694

4694

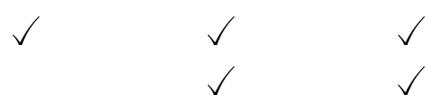

Note: Errors are clustered at the firm level. ${ }^{* * *}$ significant at the $1 \%$ level, ${ }^{* *}$ significant at the $5 \%$ level, *significant at the $10 \%$ level.

Exporters in our model are cleaner because they invest more in abatement (clean air technology). Table 2 shows that this is very well in line with the data. As explained above, this sample consists of larger firms that are to a very large degree exporters (150 out of 4694 are non-exporters). The table shows that exporters invest more in abatement and they do so also after controlling for productivity, i.e., trade has an effect on abatement investments that is independent of productivity. The effect survives when we use firm fixed effects in column (5).

Table 3: Abatement investments per output

\begin{tabular}{lccccc}
\hline Dependent var: $\log ($ Investments in cleaner technology (air) & per output) & \\
& $(1)$ & $(2)$ & $(3)$ & $(4)$ & $(5)$ \\
\hline Export dummy & $2.21^{* *}$ & $2.22^{* *}$ & $4.07^{* * *}$ & $3.94^{* * *}$ & 3.58 \\
& $(1.076)$ & $(0.937)$ & $(1.026)$ & $(1.011)$ & $(2.21)$ \\
& & & & & \\
Log(productivity) & & $-0.27^{*}$ & $-1.035^{* * *}$ & $-1.020^{* * *}$ & 0.38 \\
& & $(0.157)$ & $(0.188)$ & $(0.186)$ & $(0.633)$ \\
Sector fixed effects (5-digits) & & & & & $\checkmark$ \\
Year fixed effects & & & & $\checkmark$ & $\checkmark$ \\
Firm fixed effects & & & & & $\checkmark$ \\
\hline Number obs. & 451 & 451 & 451 & 451 & 451 \\
\hline
\end{tabular}

Note: Errors are clustered at the firm level. ${ }^{* * *}$ significant at the $1 \%$ level, ${ }^{* *}$ significant at the $5 \%$ level, *significant at the $10 \%$ level.

Finally, in Table 3 we turn to abatement investments per output. Our theoretical results are driven by scale economies in abatement. Larger firms invest more in abatement, but 
it is not obvious that they will invest more per output in the presence of scale economies in abatement. Our model actually predicts that more productive firms will invest less per output, whereas exporting increases abatement investments per output. The coefficients on productivity are negative and significant and the coefficients for the export dummy are positive and significant in all cases except when we use firm level fixed effects.

\section{The Model}

We develop a two-country model with international trade and heterogeneous firms based on Melitz (2003), where firms' production entails environmental emissions. Due to environmental regulation, these emissions are subject to taxation. Firms are either productive enough to set up production and make positive profits or they exit the market right away. If they stay, they make two distinct decisions: (i) whether or not to enter the export market, and (ii) how much to invest in abatement to reduce emissions. There is a crucial difference between the export and the abatement decision. If a firm decides to export, it has to incur a market entry cost that is constant and identical across all firms. In contrast, firms' abatement investments are endogenous and firm specific. As we will show, the optimal abatement investment turns out to depend on firm productivity as well as on whether or not the firm is exporting.

We consider the case of two countries, Home and Foreign, and let the latter be denoted by an $\operatorname{asterix}(*)$. The countries are identical with respect to technology and consumer

preferences. Each economy is active in the production in two industries: a monopolistic competitive industry $(M)$ where firms produce differentiated goods under increasing returns and subject to environmental emissions, and a perfectly competitive industry $(A)$ which produces homogeneous goods subject to constant returns to scale. To make things simple, we shall assume that there is just one factor of production. This may be a composite factor but, for the sake of simplicity, we shall refer to it as labor. The supply of labor in each country is fixed, but the size of countries may differ. (We will impose symmetric labor supplies from section 3.7 and onwards.) We present the equations describing Home's consumers and firms, and note that the corresponding equations apply to Foreign.

\subsection{Demand}

Consumer preferences are given by a two-tier utility function with the upper tier (CobbDouglas) determining the representative consumer's division of expenditure between goods produced in sectors $A$ and $M$, and the second tier (CES) representing the consumer's preferences over the continuum of differentiated varieties produced within the manufacturing 
sector. In addition, we assume that consumers are hurt by global environmental emissions $\left(E_{W}\right)$, and how much a representative consumer is hurt by a given level of emissions depends on $g\left(E_{W}\right)$. Consequently, consumer preferences can be described by the utility function

$$
U=C_{M}^{\mu} C_{A}^{1-\mu}-g\left(E_{W}\right)
$$

where $\mu \in(0,1)$, and $C_{A}, C_{M}$ constitute the consumption of the homogeneous good and the differentiated good, respectively. The function $g\left(E_{W}\right)$ measures the disutility associated with emissions, and it is assumed that $g^{\prime}\left(E_{W}\right)>0$. Goods produced in the $A$ sector can be costlessly traded internationally and are produced under constant returns to scale and perfect competition. We assume that the demand for $A$ goods is sufficiently large to guarantee that the $A$ sector is active in both countries. The $A$-good is chosen as the numeraire, and the world market price of the agricultural good, $p_{A}$, is thus equal to unity. By choice of scale, the labor requirement in the A-sector is one, which gives

$$
p_{A}=w=1
$$

and thus, wages are equal to one across both countries and sectors. Consumer preferences over goods from the $M$ sector are represented by $C_{M}$, which is an aggregate over a continuum of varieties indexed by $i$ :

$$
C_{M}=\left[\int_{i \in I} c(i)^{(\sigma-1) / \sigma} d i\right]^{\sigma /(\sigma-1)}
$$

where $c(i)$ represents consumption of each variety with elasticity of substitution between any pair of differentiated goods being $\sigma>1$. The measure of the set $I$ represents the mass of varieties consumed in each country. Each consumer spends a share $\mu$ of his income on goods from industry $M$, and the demand for each single variety produced locally and in the foreign country is, respectively, given by

$$
\begin{aligned}
x_{i}^{D} & =\frac{p_{i}^{-\sigma}}{P^{1-\sigma}} \mu L \\
x_{i}^{X} & =\frac{\tau^{1-\sigma}\left(p_{i}^{*}\right)^{-\sigma}}{P^{1-\sigma}} \mu L
\end{aligned}
$$

where $p_{i}$ is the price of variety $i, L$ is income, and $P$ is the price index of $M$ goods. $P$ is given by 


$$
P=\left(\int_{i \in I} p_{i}{ }^{1-\sigma} d G\right)^{\frac{1}{1-\sigma}}
$$

$M$-goods that are produced in Foreign (Home) and sold in Home (Foreign) incur an iceberg trade cost $\tau$. For each unit of a good that is exported from one country, $\tau>1$ units must be shipped for one unit to arrive in the other country.

\subsection{Entry, Exit and Production Costs}

There is a large pool of prospective entrants to industry $M$. To enter the $M$ industry in country $j$, a firm $i$ bears the fixed costs of entry $f_{E}$ measured in labor units. After having sunk $f_{E}$, an entrant draws a labor-per-unit-output coefficient $a_{i}$ from a cumulative distribution $G(a)$. We follow Helpman et al. (2004) in assuming the probability distribution to be a Pareto distribution, ${ }^{5}$ i.e.

$$
G(a)=\left(\frac{a}{a_{0}}\right)^{k}
$$

$k$ is the shape parameter of the distribution, and we normalize the scale parameter to unity, $a_{0}=1$. Since $a_{i}$ is the unit labor requirement of firm $i, 1 / a_{i}$ depicts the labor productivity of the firm. Upon observing its draw, a firm may decide to exit and not produce. If it chooses to stay, it bears the additional fixed overhead cost $f_{D}$. If the firm does not only want to serve the domestic market but also wants to export, it has to bear the additional fixed cost $f_{X}$. Both are constant across firms. Hence, firm technology is represented by a cost function that exhibits a variable cost and a fixed overhead cost. In the absence of emissions and abatement investment, labor is used as a linear function of output according to

$$
l_{i}=f+a_{i} x_{i}
$$

with $f=f_{D}$ for firms only serving the domestic market and $f=f_{D}+f_{X}$ for exporters. ${ }^{6}$

The industrial activity in industry $M$ entails pollution in terms of environmental emissions. These emissions are subject to taxation and a firm thus has an incentive to reduce emissions. For the sake of simplicity, we shall assume that the tax income arising from taxing

\footnotetext{
${ }^{5}$ This assumption is consistent with the empirical findings by e.g. Axtell (2001).

${ }^{6}$ Since we only have one factor of production, we make the simplifying assumption that not just variable costs, but also all types of fixed costs, are incurred in labor. However, since we do not focus on issues related to factor markets or comparative advantage, this only serves as means of simplifying the analysis, without having any impact on the results.
} 
emissions goes to an outside public good. In the modeling of emissions, we follow Copeland and Taylor (2003) and assume that each firm $i$ produces two outputs: an industrial good $\left(x_{i}\right)$ and emissions $\left(e_{i}\right)$. In order to reduce emissions, a firm can divert a fraction $\theta_{i}$ of the primary factor, labor, away from the production of $x_{i}$. We consider $\theta_{i}$ as a variable abatement cost that is chosen by each firm in order to maximize profits. The joint production of industrial goods and emissions is given by

$$
\begin{aligned}
x_{i} & =\left(1-\theta_{i}\right) \frac{l_{i}}{a_{i}} \\
e_{i} & =\varphi\left(\theta_{i}, f_{A i}\right) \frac{l_{i}}{a_{i}}
\end{aligned}
$$

with $0 \leq \theta_{i}<1$. Emissions depend on the activity level as well as the firm's abatement efforts. The abatement function

$$
\varphi\left(\theta_{i}, f_{A i}\right)=\frac{\left(1-\theta_{i}\right)^{1 / \alpha}}{h\left(f_{A i}\right)}
$$

with $0 \leq \theta_{i}<1,0<\alpha<1, f_{A i} \geq 0, h^{\prime}\left(f_{A i}\right)>0$ and $h(0)=1$ determines the level of emissions for a given activity level. We depart from the standard formulation of the abatement function in the literature by assuming that firms' abatement technology does not only have a variable cost element $\left(\theta_{i}\right)$, but also a fixed cost element $\left(f_{A i}\right)$ which represents the investment in technology, machines and equipment. The abatement function reflects the fact that firms may reduce their emissions and the emission intensity through these two different types of abatement efforts, and that the efficiency of the variable abatement activities depends on a firm's fixed abatement investment. A given reduction of emissions may be reached either through increased variable abatement $\operatorname{costs}\left(\theta_{i}\right)$ or through increased abatement investments $f_{A i}$.

Our modeling of the abatement function, in particular the introduction of both a variable and a fixed abatement cost, is novel. It is inspired by survey information on Swedish manufacturing industries that reveals the structure of the abatement costs of Swedish firms. To our knowledge, we are the first to model abatement in a way that closely mirrors the firms' actual abatement technology. As we will show, the modeling of abatement is essential for the relationship between trade and abatement and thus, for the predictions of trade liberalization and environmental emissions.

We proceed by using (10) to substitute for $\varphi$ in (9), which can then be solved for $\left(1-\theta_{i}\right)$, and, in turn, be used to substitute for $\left(1-\theta_{i}\right)$ in (8). This gives us an integrated expression for the joint production of goods and emission, which exploits the fact that although pollution 
is an output, it can equivalently also be treated as an input: ${ }^{7}$

$$
x_{i}=\left(h\left(f_{A i}\right) e_{i}\right)^{\alpha}\left(\frac{l_{i}}{a_{i}}\right)^{1-\alpha} .
$$

Hence, with such an interpretation, production implies the use of labor as well as emissions. The model is based on an underlying assumption of an imperfect substitutability between labor and emissions. The parameter $\alpha$ denotes how intensive the industry $M$ is in the use of labor versus the use of emissions. A "dirty" industry will thus be characterized by a high $\alpha$.

Note that while firms are heterogeneous with respect to labor productivity and abatement, they are identical with respect to the structure of their basic production technology. Firms minimize their costs subject to the production function $(11)$, taking wages $(w=1)$ and emission taxes $(t>0)$ as given. Disregarding the sunk entry cost, we can derive firms' total cost function using (7) and (11).

$$
C_{i}=f+f_{A i}+\kappa\left(\frac{t}{h\left(f_{A i}\right)}\right)^{\alpha} a_{i}^{(1-\alpha)} x_{i}
$$

with $\kappa \equiv \alpha^{-\alpha}(1-\alpha)^{\alpha-1}$ and $t>1$ being the emission tax. We have that $f=f_{D}$ for firms only serving the domestic market, and $f=f_{D}+f_{X}$ for exporters, i.e. firms serving both the domestic and the foreign market. The cost function reflects that emissions are not for free. But by increasing their investments in abatement, firms can reduce their emissions as well as their tax bill.

Our analysis focuses on steady-state equilibria and intertemporal discounting is ignored. The present value of firms is kept finite by assuming that firms face a constant Poisson hazard rate $\delta$ of "death" independently of productivity. An entering firm with productivity $a_{i}$ will immediately exit if its profit level $\pi\left(a_{i}\right)$ is negative, or will produce and earn $\pi\left(a_{i}\right) \geq 0$ in every period until it is hit by a bad shock and forced to exit.

\subsection{Pricing and profit}

Having drawn their productivity, firms follow a two-step decision process. We solve their problem using backward induction: First, firms calculate their optimal pricing rule given investments in local production facilities $\left(f_{D}\right)$, export facilities $\left(f_{X}\right)$ and abatement $\left(f_{A_{i}}\right)$. Second, they make their decision on firm-specific abatement investment, given the optimal pricing rule. Implicitly, they then also decide on the emission intensity and the share of the input factor to divert away from production and towards abatement, i.e. the variable

\footnotetext{
${ }^{7}$ See Copeland and Taylor (2003) for a discussion of this feature of the model.
} 
abatement efforts. At the second stage, they also decide on whether or not to export. As will become clear, the decisions on export and abatement investment are intertwined.

Each producer operates under increasing returns to scale at the plant level, and in line with Dixit and Stiglitz (1977), we assume there to be a large group monopolistic competition between the producers in the $M$ sector. Thus, the perceived elasticity of demand equals the elasticity of substitution between any pair of differentiated goods and is equal to $\sigma$. Each firm sets a price equal to a markup over marginal costs, which yields a pricing rule

$$
p_{i}=\frac{\sigma}{\sigma-1} \kappa\left(\frac{t}{h\left(f_{A i}\right)}\right)^{\alpha} a_{i}^{(1-\alpha)}
$$

for each producer. Using (12) and (13), we can formulate the expression for firms' profits. Super- and subscript $D$ and $X$ denote non-exporters and exporters, respectively. Firms only serving the domestic market will earn profits

$$
\pi_{D i}=\left(a_{i}^{1-\alpha}\left(\frac{t}{h\left(f_{A i}\right)}\right)^{\alpha}\right)^{1-\sigma} B-f_{D}-f_{A i}
$$

while the exporting firms, serving both the local and the foreign market, will earn profits

$$
\pi_{X i}=\left(a_{i}^{1-\alpha}\left(\frac{t}{h\left(f_{A i}\right)}\right)^{\alpha}\right)^{1-\sigma}\left(B+\phi B^{*}\right)-f_{D}-f_{X}-f_{A i}
$$

where $B \equiv \frac{\kappa^{1-\sigma} \sigma^{-\sigma}(\sigma-1)^{\sigma-1} \mu L}{P^{1-\sigma}}$ in an index of the market potential of the home country, $B^{*} \equiv$ $\frac{\kappa^{1-\sigma} \sigma^{-\sigma}(\sigma-1)^{\sigma-1} \mu L^{*}}{\left(P^{*}\right)^{1-\sigma}}$ depicts the market potential of the foreign country and $\phi \equiv \tau^{1-\sigma} \in\langle 0,1]$ depicts the freeness of trade.

\subsection{Cut off Conditions}

Upon entry with a low-productivity draw, a firm may decide to immediately exit and not produce. If it faces a high productivity draw and decides to stay, it may just serve the domestic market or it may choose to serve the foreign market as well. The cut-off conditions determine whether or not a firm decides to stay in the market and whether it decides to become an exporter. Firms' abatement investments affect production, marginal costs and profits and also the cut-off conditions. Abatement investments thereby have an impact on the profitability of being a domestic versus an exporting firm. ${ }^{8}$

The cut-off productivity level for firms only serving the domestic market $\left(1 / a_{D}\right)$ identifies

\footnotetext{
${ }^{8}$ In this sense, our model is related to the literature on trade-induced technological upgrading. See e.g. Bas (2008) and Bustos (2011).
} 
the lowest productivity level of producing firms. From (14) and (15), we see that profits are increasing in firms' productivity. Firms with a productivity below $1 / a_{D}$ expect negative profits and therefore exit the industry. The point at which profits from domestic sales equal zero is determined by

$$
\left(a_{D}^{1-\alpha}\left(\frac{t}{h\left(f_{A}^{D}\right)}\right)^{\alpha}\right)^{1-\sigma} B=f_{D}+f_{A}^{D}
$$

Since $\sigma>1$ and $0<\alpha<1$, it follows that $a^{(1-\alpha)(1-\sigma)}$ increases along with productivity and can thus be used as a productivity index. From (16), it follows that the cut-off productivity $a_{D}$ depends on the domestic market potential, the domestic fixed costs, taxes and abatement investment. $f_{A}^{D}$ depicts the abatement investment undertaken by the non-exporter with cutoff level productivity.

The cut-off productivity level for exporters $\left(a_{X}\right)$ identifies the lowest productivity level of exporting firms, and is given by the productivity level where the export profits plus the potential net extra profit in the home market from higher abatement investments equal the extra fixed costs incurred by exporting and the incremental investment in abatement:

$$
\begin{gathered}
\left(a_{X}^{1-\alpha}\left(\frac{t}{h\left(f_{A}^{X}\right)}\right)^{\alpha}\right)^{1-\sigma} \phi B^{*}+( \\
\left.\left(a_{X}^{1-\alpha}\left(\frac{t}{h\left(f_{A}^{X}\right)}\right)^{\alpha}\right)^{1-\sigma}-\left(a_{X}^{1-\alpha}\left(\frac{t}{h\left(f_{A}^{D}\right)}\right)^{\alpha}\right)^{1-\sigma}\right) B \\
=f_{X}+f_{A}^{X}-f_{A}^{D}
\end{gathered}
$$

where $f_{A}^{X}$ is the abatement investment chosen by the exporter with exporter cut-off level productivity. The model is closed by the free-entry condition

$$
f_{E}=\int_{0}^{a_{X}} \pi_{X} d G(a)+\int_{a_{X}}^{a_{D}} \pi_{D} d G(a)
$$

\subsection{Abatement Investment}

In order to be able to derive an explicit analytical expression for abatement investments, we employ the specific functional form $h\left(f_{A}\right)=f_{A}^{\rho}$, with $\rho>0$. From (14) and (15), it follows that firms' export decision will be decisive for firms' abatement investment and vice versa. Maximizing non-exporting firms' profits with respect to abatement investments $f_{A i}$ using (14) gives:

$$
f_{A i}^{D}=(1-\beta)^{\frac{1}{\beta}} B^{\frac{1}{\beta}} t^{-\frac{\alpha(\sigma-1)}{\beta}} a_{i}^{-\frac{\gamma}{\beta}}
$$

with $\beta \equiv 1-\alpha \rho(\sigma-1)>0$ and $\gamma \equiv(1-\alpha)(\sigma-1)>0$. We note that $\beta>0$ does not follow from the assumptions on parameter values, but from the condition for profit maximization, see Section A.1 in the Appendix. The optimal investment in abatement 
for exporters is similarly found by maximizing exporting firms' profit (15) with respect to abatement investment:

$$
f_{A i}^{X}=(1-\beta)^{\frac{1}{\beta}}\left(B+\phi B^{*}\right)^{\frac{1}{\beta}} t^{-\frac{\alpha(\sigma-1)}{\beta}} a_{i}^{-\frac{\gamma}{\beta}}
$$

From (19) and (20), we see that the optimal abatement investment is firm specific and depends on the exogenously given firm-specific marginal productivity. Higher productivity means higher abatement investments. Hence, we can formulate the following propositions on the relationship between abatement investments, productivity and exporting:

Proposition 1. More productive firms invest more in abatement.

Proof. The statement follows directly from (19) and (20).

The logic behind this result is that more productive firms have higher sales. Hence, the exploiting of scale economies makes it profitable for them to invest more in abatement in order to reduce the marginal costs.

Proposition 2. For any given level of productivity, exporters would invest more in abatement than non-exporters.

Proof. Since $\left(\frac{B+\phi B^{*}}{B}\right)^{\frac{1}{\beta}}>1$, it follows from (19) and (20) that $f_{A}^{X}>f_{A}^{D}$ for any given productivity level $(1 / a)$.

For any given level of productivity, exporters invest more in abatement since the abatement investment is correlated with the firm's market potential. Thus, trade has an independent effect on abatement, and e.g. a higher foreign market potential $B^{*}$ would increase a firm's abatement investments given productivity. ${ }^{9}$

Optimal abatement investments depend on taxes. The direct impact of the tax rate seen from expressions (19) and (20) is possibly not quite intuitive. But the effect of taxes on abatement investments also runs through the impact of taxes on a firm's competitors and thus on the firm's market potential $B$. If the firm's competitors face a higher tax rate, then ceteris paribus this encourages the firm to invest more in abatement. Due to the twofold effect of taxes on a firm's abatement investment, the net effect of taxes on abatement investments is in general ambiguous. It follows from the expressions for the market potential $(B)$, the price index $(P)$ and the price $\left(p_{i}\right)$ that with symmetric countries and tax rates (a case we explore in section 3.7), the direct and indirect effect of the tax rate cancel each other out. As a result, in the symmetric case, the abatement investments will be independent

\footnotetext{
${ }^{9}$ This property, which agrees well with our stylized evidence, is not present in models where abatement is specified as a function of firm productivity.
} 
of the emission tax rate, while the abatement intensity increases. Note also that variable abatement increases in the tax rate as we show below.

Fixed versus Variable Abatement Costs Fixed abatement investments constitute a central and novel feature of our model. It is instructive to compare how the variable abatement cost and the fixed abatement investment react to changes in the firm's environment. Using (8) and (9) and Shepard's lemma on the cost function allows us to calculate the variable abatement costs as being the share of labor that is dedicated to variable abatement activities

$$
\theta_{i}=1-(\alpha \kappa)^{\frac{\alpha}{1-\alpha}} t^{-\alpha} f_{A i}^{\rho \alpha} a_{i}^{\alpha} .
$$

This expression leads to the following proposition:

Proposition 3. Variable abatement costs measured in terms of the share of labor diverted away from the production of good $x$, increases in firm productivity and in the tax rate, and decreases in the firm's fixed abatement investment.

Proof. The statement follows directly from (21).

Hence, higher productivity leads to increased output but also to more resources being directed towards abatement both in terms of variable abatement costs and fixed abatement costs, and a tax increase encourages increased variable abatement costs. We also observe that there is a substitution between the two types of abatement costs. A higher fixed abatement investment leads to lower variable abatement efforts. Finally, we observe that while trade costs have a direct impact on fixed abatement investment, there is no impact of trade costs on variable abatement efforts. Hence, for trade liberalization to affect abatement efforts, environmental abatement must be characterized by economies of scale at the firm level.

\subsection{Environmental Emissions}

A firms' choice of emissions will depend on the relative price of emissions versus labor and its abatement investments. The general expression for emission intensity is found by using Shepard's lemma on the cost function (12): ${ }^{10}$

$$
\frac{e_{i}}{x_{i}}=\alpha \kappa t^{\alpha-1} f_{A i}^{-\rho \alpha} a_{i}^{1-\alpha}
$$

\footnotetext{
${ }^{10}$ Note that emissions implied by transportation are accounted for in the analysis due to how they are modeled. Iceberg transportation costs imply that transportation costs are incurred in terms of the good transported, and emissions related to the production of the quantity that is absorbed by transportation are thus accounted for in all expressions of emissions and emission intensity of exporters.
} 
To explore the relationship between emission intensity and firm characteristics, we proceed by deriving the emission intensity of an exporter and a non-exporter, respectively. We substitute (19) and (20) into (22) to get:

$$
\begin{gathered}
\frac{e_{i}^{D}}{x_{i}}=\alpha \kappa t^{\frac{\alpha-\beta}{\beta}} B^{-\frac{\rho \alpha}{\beta}}\left(\frac{1}{1-\beta}\right)^{\frac{\rho \alpha}{\beta}} a_{i}^{\frac{1-\alpha}{\beta}} \\
\frac{e_{i}^{X}}{x_{i}}=\alpha \kappa t^{\frac{\alpha-\beta}{\beta}}\left(B+\phi B^{*}\right)^{-\frac{\rho \alpha}{\beta}}\left(\frac{1}{1-\beta}\right)^{\frac{\rho \alpha}{\beta}} a_{i}^{\frac{1-\alpha}{\beta}} .
\end{gathered}
$$

We see that firms' participation in trade affects their investment in abatement and therefore their emission intensity, measured as emissions relative to output. A set of results on the relationship between emission intensity, productivity and trade emerges directly from equations (23) and (24):

Proposition 4. More productive firms have a lower emission intensity.

Proof. The statement follows directly from equations (23) and (24).

Proposition 5. For any given level of productivity, an exporter would have a lower emission intensity than a non-exporter.

Proof. The statement follows from the cut-off conditions for exporters and non-exporters, expressions (23) and (24), and the fact that $\left(B+\phi B^{*}\right)^{-\frac{\rho \alpha}{\beta}}<B^{-\frac{\rho \alpha}{\beta}}$.

More productive firms have a lower emission intensity, both due to a higher efficiency in their use of inputs and due to their higher investments in abatement (see Proposition 1). Hence, in the absence of endogenous investments in abatement $\left(\rho=0\right.$ or $\left.f_{A i}=f_{A}\right)$, more productive firms still have a lower emission intensity.

Since exporters are more productive than non-exporters, it follows that exporters will have a lower emission intensity than non-exporters. However, without endogenous abatement investments, the difference in emission intensity between exporters and non-exporter is purely driven by the productivity differences between the firms per se, and is unrelated to trade. Once we assume endogenous investments in abatement, trade has direct implications for abatement and emission intensity. Independent of firm productivity, the increased production scale implied by exporting leads to higher abatement investments (see (19) and (20)) and a lower emission intensity. 


\subsection{Trade Liberalization, Abatement and Emissions}

We will now turn to the effects of lower variable trade costs (higher $\phi) .{ }^{11}$ In order to analyze the effects of incremental trade liberalization, we need to solve the model completely, and therefore now assume the two economies to be symmetric. Due to symmetry, it suffices to solve for equilibrium in Home. Emission taxes are fixed and identical in the two economies. Using equations (19), (20), (16), (17), and (18), we can solve for the endogenous variables $f_{A}^{D}, f_{A}^{X}, a_{D}, a_{X}$, and $B$. This gives us the following two expressions for the cut-off productivities: ${ }^{12}$

$$
\begin{aligned}
a_{D}^{k} & =\frac{f_{E}}{\left(\frac{\gamma}{k \beta-\gamma}\right) f_{D}\left(\left((\phi+1)^{\frac{1}{\beta}}-1\right)^{\frac{k \beta}{\gamma}} f_{D}^{\frac{k \beta}{\gamma}-1} f_{X}^{1-\frac{k \beta}{\gamma}}+1\right)} \\
a_{X}^{k} & =\frac{f_{E}}{\left(\frac{\gamma}{k \beta-\gamma}\right) f_{X}\left(1+\left((\phi+1)^{\frac{1}{\beta}}-1\right)^{-\frac{k \beta}{\gamma}} f_{X}^{\frac{k \beta}{\gamma}-1} f_{D}^{1-\frac{k \beta}{\gamma}}\right)},
\end{aligned}
$$

with $\beta \equiv 1-\alpha \rho(\sigma-1), \beta \in(0,1)$, and $\gamma \equiv(1-\alpha)(\sigma-1)>0$. Note that if production does not entail any emissions and we accordingly assume $\alpha=0$, the equilibrium expressions reduce to the standard Melitz (2003) cut-off conditions. ${ }^{13}$ Exporters are more productive than non-exporters, i.e. $a_{X}<a_{D}$, as long as $\frac{f_{X}}{f_{D}\left((1+\phi)^{\frac{1}{\beta}}-1\right)}>1$, and we assume this to hold throughout the analysis. ${ }^{14}$ We also assume that $k \beta>\gamma$, which guarantees that the cut-off productivities are positive. ${ }^{15}$ From (25) and (26), it follows that trade liberalization will make the domestic cut-off condition tougher, i.e. $a_{D}$ decreases, while the exporter cut-off condition becomes softer, i.e. $a_{X}$ increases, as trade liberalization allows the entry of new firms into the export market. These results are in line with the results in the standard Melitz model.

By solving for the price index in the symmetric case, and using (25) and (26), we can derive the equilibrium number of firms in Home (being identical to the number of firms in foreign), which will matter for total emissions in equilibrium:

\footnotetext{
${ }^{11}$ It is also possible to think of trade liberalization as a lower market entry cost, $f_{X}$. However, lower variable trade costs (a higher $\phi$ ) and lower $f_{X}$ turns out to have qualitatively the same effects on our model, and we therefore here focus on variable trade cots.

${ }^{12}$ See Appendix Section A.4 for details on calculation.

${ }^{13}$ For a comparison of equilibrium cut off conditions, see Baldwin and Forslid (2010) who derive explicit expressions for the standard Melitz (2003) model cut-off conditions for the symmetric case without emissions.

${ }^{14}$ The corresponding condition in the standard Melitz model is $\frac{f_{X}}{f_{D} \phi}>1$.

${ }^{15}$ The condition may be written: $\frac{k}{\sigma-1}>1-\alpha+\alpha k \rho$, which reduces to the standard condition in the Melitz (2003) model that $\frac{k}{\sigma-1}>1$ for $\alpha=0$.
} 


$$
n=\frac{(k \beta-\gamma) \mu L}{f_{D} \sigma k\left(1+\left((\phi+1)^{\frac{1}{\beta}}-1\right)^{\frac{k \beta}{\gamma}}\left(\frac{f_{D}}{f_{X}}\right)^{\frac{k \beta}{\gamma}-1}\right)} .
$$

It follows from (27) that as is standard in the Melitz model, the number of firms in Home and, by symmetry, in Foreign, decreases as trade is liberalized.

\subsubsection{Trade Liberalization and Abatement Investments}

We start by examining the impact of trade liberalization on abatement investments. For this purpose, we derive explicit expressions for firms' abatement investments in the symmetric case. We proceed by using (16) and substitute for the cut-off productivity for non-exporters determined by $(25)$ to back out $B$. Using the explicit expression for $B$ and the fact that $B=B^{*}$ in the symmetric case, we substitute into (19) and (20), and derive the abatement investments for non-exporters $\left(f_{A}^{D}\right)$ and exporters $\left(f_{A}^{X}\right)$ for the symmetric equilibrium:

$$
\begin{gathered}
f_{A i}^{D}=f_{D}\left(\frac{1-\beta}{\beta}\right)\left(\frac{a_{i}}{a_{D}}\right)^{-\frac{\gamma}{\beta}} \\
\left.=f_{D}\left(\frac{1-\beta}{\beta}\right)\left(\frac{\left(\frac{k \beta}{\gamma}-1\right) f_{E}}{f_{D}\left(\left((1+\phi)^{\frac{1}{\beta}}-1\right)^{\frac{k \beta}{\gamma}}\left(\frac{f_{D}}{f_{X}}\right)^{\frac{k \beta}{\gamma}-1}+1\right)}\right)\right)^{\frac{\gamma}{k \beta}} a_{i}^{-\frac{\gamma}{\beta}} \\
f_{A i}^{X}=f_{D}\left(\frac{1-\beta}{\beta}\right)(1+\phi)^{\beta}\left(\frac{a_{i}}{a_{D}}\right)^{-\frac{\gamma}{\beta}}\left(\frac{\left(\frac{k \beta}{\gamma}-1\right) f_{E}}{f_{D}\left(\left((1+\phi)^{\frac{1}{\beta}}-1\right)^{\frac{k \beta}{\gamma}}\left(\frac{f_{D}}{f_{X}}\right)^{\frac{k \beta}{\gamma}-1}+1\right)}\right)^{\frac{\gamma}{k \beta}} a_{i}^{-\frac{\gamma}{\beta}} \\
=f_{D}\left(\frac{1-\beta}{\beta}\right)(1+\phi)^{\beta}
\end{gathered}
$$

Based on (28) and (29), we can now formulate the following proposition on the effect of trade liberalization on abatement investments:

Proposition 6. Trade liberalization (higher $\phi$ ) will always decrease non-exporting firms' abatement investments, and it will increase exporters' abatement investments iff

$$
\frac{\gamma}{k \beta}<\beta^{2}\left(1-\left(1-\left(\frac{f_{X}}{f_{D}}\right)^{\frac{k \beta}{\gamma}-1}\right)(1+\phi)^{-\frac{1}{\beta}}\right) .
$$

Proof. It follows directly from (28) that trade liberalization leads to reduced abatement investments among non-exporters, while the condition for exporters is derived in Appendix A.2. 
Trade liberalization increases the competition for all firms. This effect is most easily seen in the first part of equations (28) and (29) where the ratio $\frac{a_{i}}{a_{D}}$ falls as trade liberalization leads to a higher $a_{D}$. This effect leads to a lower scale of production and lower abatement investments among all firms. However, for exporters, trade liberalization also means improved market access to the foreign market and increased export sales. This is reflected by the term $(1+\phi)^{\beta}>1$ in $(29)$. The net impact of trade liberalization on existing exporters is positive only if the competition effect is weaker than the effect of improved market access. Finally, trade liberalization also induces some firms to switch from non-exporting to exporting, and this increases the abatement investments of these firms by the factor $(1+\phi)^{\beta}>1$.

Using (16) and substituting for the cut off productivity for non-exporters determined by (25) to back out $B$, the demand equations (4), and (28) and (29) give the abatement intensity of non-exporters, $\left(\frac{f_{A i}^{D}}{x_{i}}\right)$, and exporters, $\left(\frac{f_{A i}^{X}}{x_{i}}\right)$ :

$\frac{f_{A i}^{D}}{x_{i}}=\frac{\kappa \beta^{\alpha \rho}}{\sigma-1}(1-\beta)^{1-\alpha \rho} f_{D}^{-\alpha \rho}\left(\frac{\left(\frac{k \beta}{\gamma}-1\right) f_{E}}{f_{D}\left(\left((1+\phi)^{\frac{1}{\beta}}-1\right)^{\frac{k \beta}{\gamma}}\left(\frac{f_{D}}{f_{X}}\right)^{\frac{k \beta}{\gamma}-1}+1\right)}\right)^{-\frac{(1-\alpha)(1-\beta)}{k \beta}} t \cdot a_{i}^{\frac{(1-\alpha)}{\beta}}$

$\frac{f_{A i}^{X}}{x_{i}}=\frac{\kappa \beta^{\alpha \rho}(1-\beta)^{1-\alpha \rho}}{(\sigma-1) f_{D}^{\alpha \rho}}(1+\phi)^{\frac{(1-\beta)}{\beta}}\left(\frac{\left(\frac{k \beta}{\gamma}-1\right) f_{E}}{f_{D}\left(\left((1+\phi)^{\frac{1}{\beta}}-1\right)^{\frac{k \beta}{\gamma}}\left(\frac{f_{D}}{f_{X}}\right)^{\frac{k \beta}{\gamma}-1}+1\right)}\right) t^{\frac{(1-\alpha)}{\beta}}$

This leads to the following propositions:

Proposition 7. Trade liberalization (higher $\phi$ ) will increase the fixed abatement intensity of both exporters and non-exporters, but the increase is sharper for exporters.

Proof. The proposition follows directly from (30) and (31) since $\beta<1$.

Proposition 8. More productive firms have a lower fixed abatement intensity.

Proof. The proposition follows directly from (30) and (31).

Trade liberalization implies a higher fixed abatement intensity for all firms, but a higher productivity actually leads to a lower abatement intensity. That is, more productive firms invest more in abatement, as revealed by (28) and (29), but abatement investments as a share of output decline in productivity. 


\subsubsection{Trade Liberalization and Emission Intensity}

Having established the effects of trade liberalization on abatement investments, we now turn to the effect of trade liberalization on emission intensity in the symmetric case. We use the general expression for emission intensity in (22) and substitute for $f_{A i}^{D}$ and $f_{A i}^{X}$ using (28) and (29). This gives us the emission intensity for non-exporters $\left(\frac{e_{i}^{D}}{x_{i}}\right)$ and exporters $\left(\frac{e_{i}^{X}}{x_{i}}\right)$

$$
\begin{aligned}
& \frac{e_{i}^{D}}{x_{i}}=\alpha \kappa\left(\frac{\beta}{f_{D}(1-\beta)}\right)^{\rho \alpha}\left(\frac{\left(\frac{k \beta}{\gamma}-1\right) f_{E}}{f_{D}\left(\left((1+\phi)^{\frac{1}{\beta}}-1\right)^{\frac{k \beta}{\gamma}}\left(\frac{f_{D}}{f_{X}}\right)^{\frac{k \beta}{\gamma}-1}+1\right)}\right)^{-\frac{\alpha \rho \gamma}{k \beta}} t^{-(1-\alpha)} a_{i}^{\frac{1-\alpha}{\beta}}(32) \\
& \frac{e_{i}^{X}}{x_{i}}=\alpha \kappa\left(\frac{\beta}{f_{D}(1-\beta)}\right)^{\rho \alpha}(1+\phi)^{-\frac{\alpha \rho}{\beta}}\left(\frac{\left(\frac{k \beta}{\gamma}-1\right) f_{E}}{f_{D}\left(\left((1+\phi)^{\frac{1}{\beta}}-1\right)^{\frac{k \beta}{\gamma}}\left(\frac{f_{D}}{f_{X}}\right)^{\frac{k \beta}{\gamma}-1}+1\right)}\right)^{-\frac{\alpha \rho \gamma}{k \beta}} t^{-(1-\alpha)} a_{i}^{\frac{1-\alpha}{\beta}}
\end{aligned}
$$

We start by pointing out that absent fixed abatement investments, i.e. if $\rho=0$, trade liberalization has no impact on the emission intensity. This follows directly from the general discussion above in Section 3.6, where we emphasized that in the absence of fixed abatement investment, trade per se does not have any impact on emission intensity. Then, from (32) and (33), we can derive the following proposition on the relationship between trade liberalization and emission intensity:

Proposition 9. Trade liberalization (higher $\phi$ ) leads to an increased emission intensity among non-exporters and a lower emission intensity among exporters.

Proof. The effect of trade liberalization on non-exporters follows immediately from (32). As for the effect of trade liberalization on exporters' emission intensity, see Section A.3 in the Appendix for proof.

Thus, trade liberalization makes exporters cleaner and non-exporters dirtier. For nonexporters, trade liberalization only means increased competition which translates into reduced sales and reduced abatement investments (Proposition 6). The weak increase in abatement intensity (Proposition 8) is not enough to prevent this group of firms from increasing their emission intensity. For exporters, trade liberalization means increased competition but also improved market access and, as shown in Proposition 8, the effect on abatement investment per output is much stronger for exporters than for non-exporters. This means that trade liberalization leads to a reduced emission intensity among exporters. 
Analyzing abatement investment, we found that in the symmetric case, the effects of taxes cancel each other out and taxes do therefore not have any impact on abatement investments, but they do affect firms' emission intensity as seen in (32) and (33). This result is due to the fact that an increase in the emission tax makes emissions more expensive and encourages the firm to increase its variable abatement efforts. As a consequence, both exporters' and non-exporters' emission intensity are reduced if the tax rate goes up.

\subsubsection{Trade Liberalization and Aggregate Emissions}

It remains to investigate whether trade liberalization reduces or increases aggregate emission volumes. Trade liberalization affects individual firms' emission intensity, their production volumes, the number of firms and the productivity cut-off levels. Adding up these effects, we are able to determine the effect of trade liberalization on global emissions. We start by examining the effect of trade liberalization on individual firms' emissions. We proceed, using $(23),(24),(4)$ and the solution for $B$ to calculate emissions for non-exporters and exporters: ${ }^{16}$

$$
\begin{gathered}
e_{i}^{D}=\frac{\alpha(\sigma-1) f_{D}}{\beta t}\left(\frac{\left(\frac{k \beta}{\gamma}-1\right) f_{E}}{f_{D}\left(\left((1+\phi)^{\frac{1}{\beta}}-1\right)^{\frac{k \beta}{\gamma}}\left(\frac{f_{D}}{f_{X}}\right)^{\frac{k \beta}{\gamma}-1}+1\right)}\right)^{\frac{\gamma}{k \beta}} a_{i}^{-\frac{\gamma}{\beta}} \\
e_{i}^{X}=\frac{\alpha(\sigma-1) f_{D}}{\beta t}(1+\phi)^{\frac{1}{\beta}}\left(\frac{\left(\frac{k \beta}{\gamma}-1\right) f_{E}}{f_{D}\left(\left((1+\phi)^{\frac{1}{\beta}}-1\right)^{\frac{k \beta}{\gamma}}\left(\frac{f_{D}}{f_{X}}\right)^{\frac{k \beta}{\gamma}-1}+1\right)}\right)^{\frac{\gamma}{k \beta}} a_{i}^{-\frac{\gamma}{\beta}} .
\end{gathered}
$$

Comparing these to (28) and (29) reveals that firms' emissions are proportional to firms' abatement investments. As is the case for abatement investments, we have that trade liberalization reduces each non-exporter's emissions, which is driven by reduced output among non-exporters due to increased competition. Hence, a lower volume more than compensates for an increased emission intensity among these firms.

Exporters' individual emission volumes are affected by trade liberalization through two channels: Trade reduces the emission intensity while at the same time increasing sales volumes. It is also noteworthy from (34) and (35) that higher productivity firms have ceteris paribus higher emissions due to the higher production volume of these firms.

\footnotetext{
${ }^{16} B$ is calculated in Appendix A.4.
} 
In order to derive the impact of trade liberalization on total global emissions, we finally need to take in account the effect of trade liberalization on firm demography. Trade liberalization is known to cause the exit of the least productive non-exporters while also allowing the most productive non-exporters to enter into exporting. Aggregate emissions by non-exporters and exporters in Home (and, by symmetry, in Foreign) are given by the integrals

$$
E_{D}=n \int_{a_{X}}^{a_{D}} e_{D} d G\left(a \mid a_{D}\right)
$$

and

$$
E_{X}=n \int_{0}^{a_{X}} e_{X} d G\left(a \mid a_{D}\right)
$$

Solving these integrals conditional upon firm entry gives the expressions for total emissions of non-exporters and exporters in each country, respectively. ${ }^{17}$ Aggregate emissions of non-exporters are given by

$$
E_{D}=\frac{\alpha(\sigma-1)\left(1-\left(\left((\phi+1)^{\frac{1}{\beta}}-1\right) \frac{f_{D}}{f_{X}}\right)^{\frac{k \beta}{\gamma}-1}\right)}{\sigma\left(1+\left((\phi+1)^{\frac{1}{\beta}}-1\right)^{\frac{k \beta}{\gamma}}\left(\frac{f_{D}}{f_{X}}\right)^{\frac{k \beta}{\gamma}-1}\right)} t^{-1} \mu L .
$$

Trade liberalization decreases the total emissions of non-exporting firms. This follows directly from (38), given the underlying assumptions that $k \beta>\gamma$. Trade liberalization reduces the number of non-exporters. Moreover, those that are weeded out are the least productive and thus the dirtiest firms. Together with lower production and emission volumes for the remaining non-exporters, this implies that trade liberalization reduces total emissions by non-exporters, despite the fact that non-exporters decrease their abatement investments and increase their emission intensities.

Aggregate emissions by exporters are given by

$$
E_{X}=\frac{\alpha(\sigma-1)\left(\left((\phi+1)^{\frac{1}{\beta}}-1\right)^{\frac{k \beta}{\gamma}-1}\left(\frac{f_{D}}{f_{X}}\right)^{\frac{k \beta}{\gamma}-1}\right)}{\sigma\left(1+\left((\phi+1)^{\frac{1}{\beta}}-1\right)^{\frac{k \beta}{\gamma}}\left(\frac{f_{D}}{f_{X}}\right)^{\frac{k \beta}{\gamma}-1}\right)}(\phi+1)^{\frac{1}{\beta}} t^{-1} \mu L .
$$

On a general basis, the effect of trade liberalization on aggregate emissions of exporters looks ambiguous, but adding aggregate emissions by exporters and non-exporters gives a clear cut-answer. Global emissions are given by:

\footnotetext{
${ }^{17}$ See the supplementary guide to calculations.
} 


$$
E_{W}=\frac{\alpha(\sigma-1)}{\sigma} t^{-1} \mu\left(L+L^{*}\right),
$$

where $E_{W}=E_{D}+E_{X}+E_{D}^{*}+E_{X}^{*}$. Thus, global emissions are not affected by trade liberalization when countries are symmetric, and since trade liberalization decreases total emissions of non-exporting firms it must be the case that total emissions of exporting firms increases.

Proposition 10. Aggregate global emissions decrease in the tax rate but are unaffected by trade costs when countries are symmetric.

Proof. The proposition follows directly from equation (40).

In order to illustrate the different effects behind this result, we follow Anouliès (2017) and Cherniwchan et al. (2017) and use (23), (24), (36) and (37) to decompose the effect of trade liberalization on aggregate emissions from one of the symmetric countries:

$$
\begin{aligned}
& \frac{d E}{d \phi}=\frac{d E_{D}}{d \phi}+\frac{d E_{X}}{d \phi}= \\
& \frac{d n}{d \phi}\left(\int_{a_{X}}^{a_{D}} e_{D} d G+\int_{0}^{a_{X}} e_{X} d G\right)+n \int_{a_{X}}^{a_{D}} \frac{d \epsilon_{D}}{d \phi} x_{D} d G+n \int_{0}^{a_{X}} \frac{d \epsilon_{X}}{d \phi} x_{X} d G \\
& +n \int_{a_{X}}^{a_{D}} \epsilon_{D} \frac{d x_{D}}{d \phi} d G+n \int_{0}^{a_{X}} \epsilon_{X} \frac{d x_{X}}{d \phi} d G+n \frac{d a_{D}}{d \phi} e_{D}\left(a_{D}\right)+n \frac{d a_{X}}{d \phi}\left(e_{X}\left(a_{X}\right)-e_{D}\left(a_{X}\right)\right),
\end{aligned}
$$

where $\epsilon_{i} \equiv \frac{e_{i}}{x_{i}}$ is the emission intensity of firm i. The first term shows the negative effect on the extensive margin where the mass of firms declines due to increased competition. The second and third term show the technology effect. The emission intensity of non-exporters increases as these firms decrease their abatement investments when import competition becomes harder. Exporters, in contrast, increase abatement investments when exporting becomes easier and this reduces their emission intensity. The opposite pattern holds for the scale effect illustrated in terms four and five. Here exporters increase their production while non-exporters scale down. The last two terms show how the selection effects in the Melitz framework lead to lower emissions. Increased competition due to trade liberalization means that dirty, low productive firms are forced out of the market, $\frac{d a_{D}}{d \phi}<0$, which decreases emissions. Finally, trade liberalization implies that some firms change status from non-exporters to exporters. This effect decreases emissions since a firm of a given productivity invests more in abatement when it becomes an exporter, $e_{X}\left(a_{X}\right)<e_{D}\left(a_{X}\right), \frac{d a_{X}}{d \phi}>0$.

We next turn to a numerical illustration of the effects of trade liberalization on emissions in our model. Figure $1^{18}$ shows a typical case of how emissions by exporters and non-exporters

\footnotetext{
${ }^{18}$ The figure is based on the parameter values: $\sigma=4, k=7, f_{E}=0.5, f_{D}=1.5, f_{X}=2.5, \alpha=0.2, \rho=$ $0.2, L=L^{*}=100, \mu=0.3$ and $t=1.2$.
} 
evolve in response to trade liberalization. The rise in the total emissions of exporters is fully compensated by the decrease in emissions by non-exporters, which means that global emissions are constant. This conclusion holds also when countries are of different size as long as everything else is symmetric. Figure 2 shows a case where all parameter values are the same as in Figure 1 except that $L>L^{*} \cdot{ }^{19}$ In this case, trade liberalization leads to a concentration of firms in the larger home country because of the so-called home-marketeffect. A larger market is ceteris paribus more attractive since it allows a firm to economize on (iceberg) transport costs. However, competition increases in the large market as more firms concentrate here, and location is determined by the balance of these forces. Trade liberalization makes it easier to serve the other market via export and this will lead more firms to locate in the larger market. While Figure 1 still applies for aggregate global emissions from exporters and non-exporters, the distribution of emissions between the two countries changes. Figure 2 shows how the relocation of firms to the larger country implies higher emissions in this country and lower emissions in the other country, while global emissions remain constant.

Contrary to e.g. Felbermayr et al. (2013) and Naito (2017), we are not able to solve our model in the asymmetric case, and we therefore below turn to numerical simulation when taxes are asymmetric.

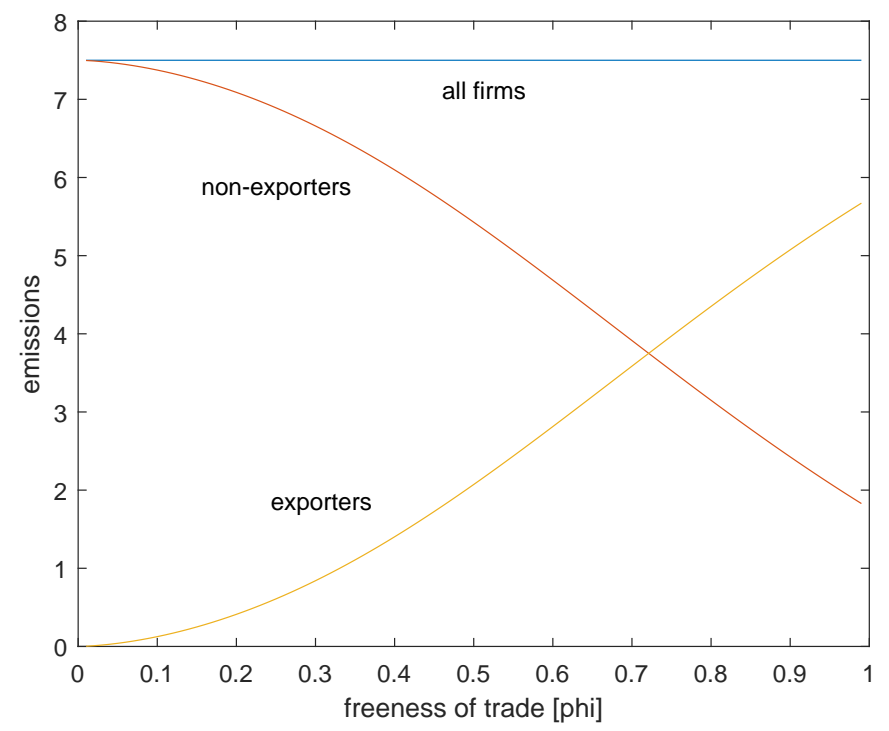

Figure 1: Trade liberalization and emissions with symmetric countries

\footnotetext{
${ }^{19}$ The figure is based on the parameter values: $\sigma=4, k=7, f_{E}=0.5, f_{D}=1.5, f_{X}=2.5, \alpha=0.2, \rho=$ $0.2, L=120, L^{*}=80, \mu=0.3$ and $t=1.2$.
} 


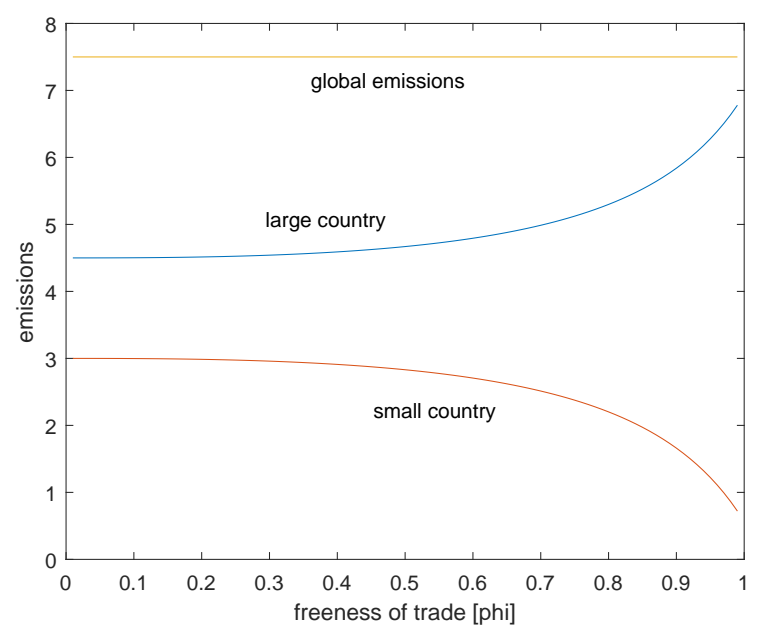

Figure 2: Trade liberalization and emissions with countries of different size

\subsubsection{An anti-pollution haven hypothesis}

We here turn to simulating the effect of trade liberalization when the home country has lower environmental taxes, $t<t^{*} .{ }^{20}$ This is a case that is potentially problematic from an environmental point of view, since lower trade costs make it easier for firms to concentrate production in the low tax location and serve the world market from here. Figure 3 shows how firms indeed concentrate in the low tax economy in a relative sense, while at the same time the number (mass) of firms is reduced as competition increases due to trade liberalization.

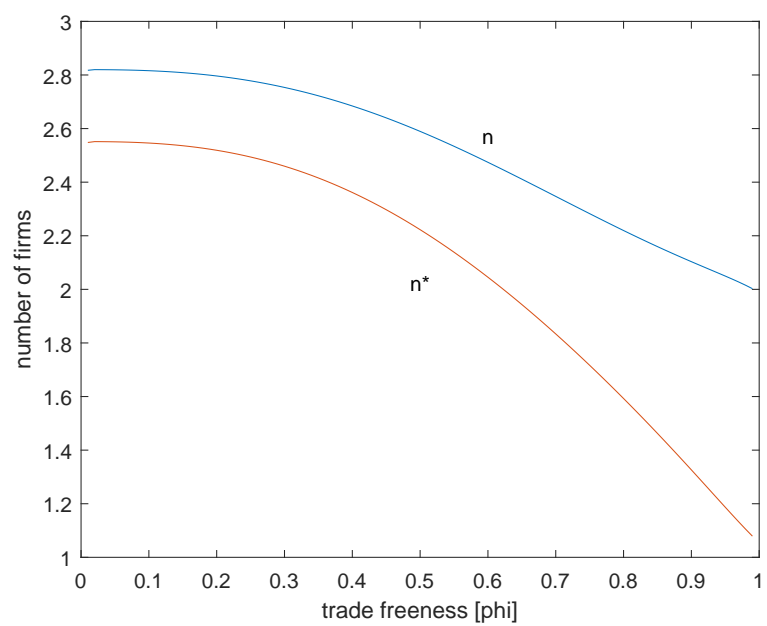

Figure 3: Trade liberalization and the number of firms in Home and Foreign when $t<t *$

\footnotetext{
${ }^{20}$ Figures 3-5 are based on the parameter values: $\sigma=4, k=7, f_{E}=0.5, f_{D}=1.5, f_{X}=2.5, \alpha=0.2, \rho=$ $0.2, L=L^{*}=100, \mu=0.3, t=1$, and $t^{*}=1.1$.
} 
The competitive pressure in the respective country is illustrated by the development of the cut-offs as shown in Figure 4. Competition is harder in Home as firms concentrate here and the marginal non-exporter has a substantially lower marginal cost $\left(a_{D}\right)$ here as compared to the foreign market. At the same time, home is attractive for exporters that enjoy an advantage in the foreign market due to a lower marginal cost because of the lower environmental tax rate. Thus, trade liberalization leads to a sharp increase in the number of exporters and a relative sharp drop in the number of non-exporters until almost all firms export in Home. This development is less pronounced in Foreign where more non-exporters survive and fewer firms start exporting.
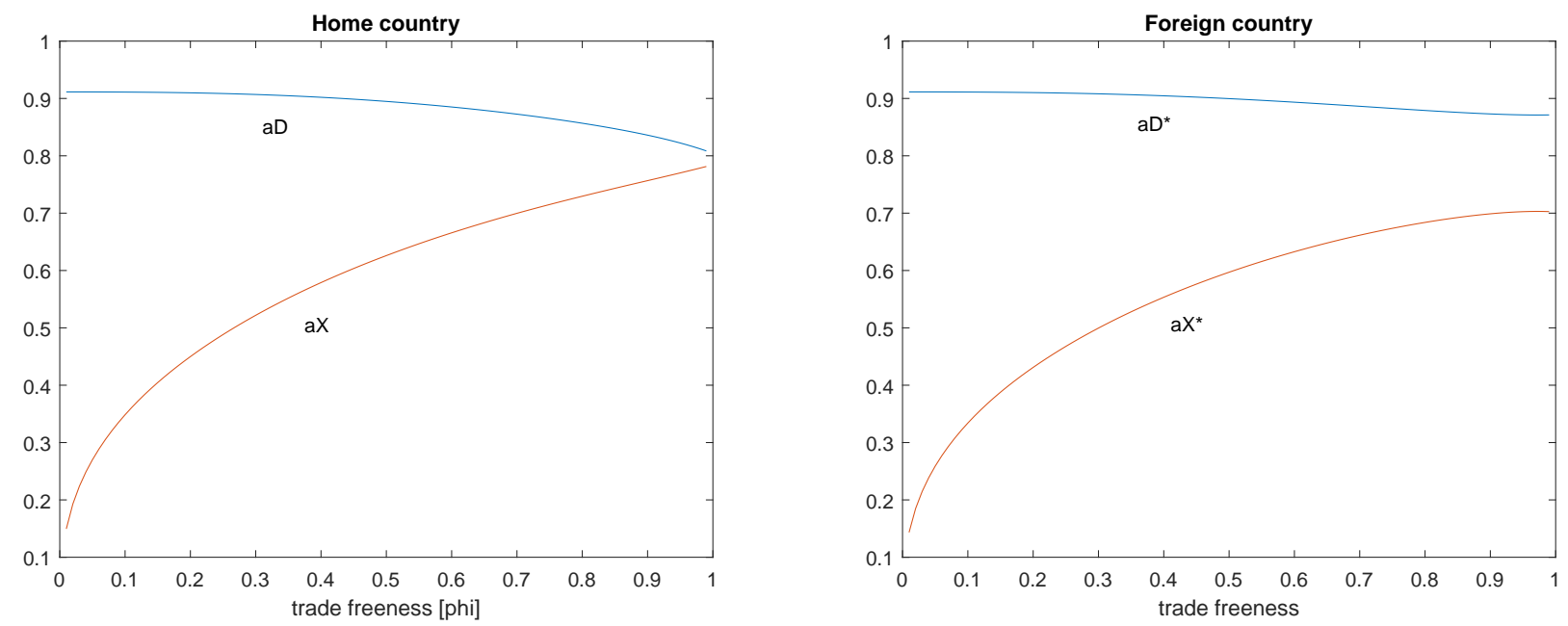

Figure 4: Trade liberalization and cut-offs in Home and Foreign when $t<t *$

The switch from non-exporting to exporting leads to higher investments in abatement, as shown in Proposition 2, and together with the closing down of many low productive and dirty firms in Home, trade liberalization leads to a very moderate increase in emissions in Home. At the same time, the emissions in Foreign drop as the number of firms fall sharply. Together, this leads to falling global emissions as seen in Figure 5.

Several forces are, as discussed, at work, but the dominating effect relates to firms switching to exporting, particularly in Home, which leads to lower emissions. This effect is so strong that global emissions decrease as trade is liberalized. This holds for a wide range of parameter values, and it is interesting to note that this framework can produce a case where global emissions decrease with trade liberalization, even though trade liberalization induces firms to concentrate in the low tax economy. Thus, we have an instance of an anti-pollution haven case where the efficiency effects (scale effects) related to trade are strong enough to outweigh the standard pollution haven hypothesis. However, note that the anti-pollution haven case hinges on firms switching to become exporters. If conditions are such that this does not 
happen, the usual pollution haven hypothesis applies. This will for instance be the case if the fixed cost of exporting is substantially higher in the low tax country. If so, then too few firms will switch to exporting and trade liberalization will in this case lead to higher global emissions. $^{21}$
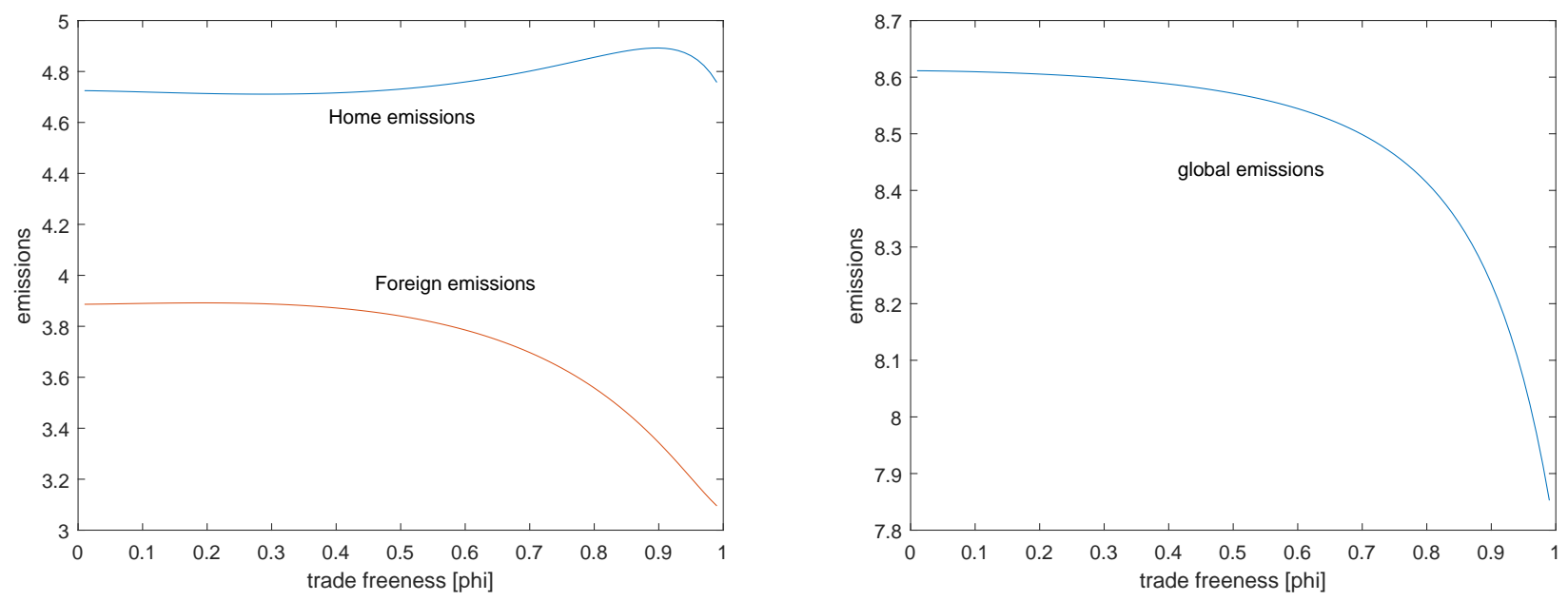

Figure 5: Trade liberalization and aggregate emissions when $t<t *$

\section{Conclusion}

This paper develops a two-country model of heterogeneous firms that invest in abatement to lower the environmental emissions. The model proposes a mechanism for why exporters may have lower emission intensities than non-exporters. Firms' abatement investments depend on their production volumes, as a larger scale allows them to spread the fixed costs of abatement investment across more units. Exporting leads to higher production volumes and thereby to a lower emission intensity. This implies that exporting has an effect on emissions that is independent of firm productivity, and the model suggests that trade has a positive effect on firms' abatement intensity (abatement per output). We show that these effects are in accordance with Swedish firm-level data.

Solving the model for symmetric countries, we find that trade liberalization allows for a higher production volume and makes exporters cleaner as they are induced to invest more in abatement. But trade liberalization also makes non-exporters dirtier as these firms are forced to downsize and reduce their investments in abatement. Reallocation effects do add to this. Trade liberalization implies increased competition and forces the most dirty non-

\footnotetext{
${ }^{21}$ The anti-pollution haven case is reversed, for the parameter values used here, when the fixed cost of exporting in the low tax country is about 16 percent higher than in the high tax country.
} 
exporters out of the market, while it also softens the threshold for exporting, allowing firms with ceteris paribus lower productivity and higher emission intensity to enter into exports. As it turns out, these effects cancel out when countries are symmetric (except for size), and aggregate emissions are therefore unaffected by trade liberalization.

Finally, we simulate a case where one country has lower emission taxes, but where trade liberalization nevertheless leads to lower global emissions. Thus, we have an anti-pollution haven effect. The reason for this effect is that firms in the low cost economy have an advantage in the export market, and when firms in this market switch to exporting, they increase their investments in abatement.

Our paper proposes a mechanism of how technology upgrading makes exporting firms cleaner. We also show that this effect can be strong enough to overturn the pollution haven hypothesis. Thus, our paper proposes one reason why the empirical literature has found it difficult to establish that trade liberalization leads to higher emissions. 


\section{References}

[1] Anouliès, L. (2017), "Heterogeneous firms and the environment: a cap-and-trade program", Journal of Environmental Economics and Management 84, pp. 84-101.

[2] Antweiler, W., B. R. Copeland and M. S. Taylor (2001), "Is Free Trade Good for the Environment?" American Economic Review 91 (4), pp. 877-908.

[3] Axtell, R. L. (2001), "Zipf distribution of U.S. firm sizes", Science 293.

[4] Baldwin, R. and R. Forslid (2010),"Trade liberalization with heterogeneous firms", Review of Economic Development,14 (2), pp.161-176 .

[5] Bas, M. (2012), "Technology Adoption, Export Status and Skill Upgrading: Theory and Evidence", Review of International Economics 20(2), pp.315-331

[6] Batrakova, S. and R. B. Davies, (2012). "Is there an environmental benefit to being an exporter? Evidence from firm level data", Review of World Economics 148(3), pp. 449-474.

[7] Bernard, A., J. Bradford Jensen, S. Redding and Peter Schott (2007), "Firms in International Trade", Journal of Economic Perspectives, 21(3), pp.105-130.

[8] Brunnermeier, S. and A. Levinson (2004), "Examining the evidence on environmental regulations and industry location", Journal of Environment and Development 13, pp.6-41.

[9] Bustos, P. (2011), "Trade Liberalization, Exports, and Technology Upgrading: Evidence on the Impact of MERCOSUR on Argentinian Firms", American Economic Review 101(1), pp. 304-340.

[10] Cao, J., L.D. Qui and M. Zhou (2016), "Who invests more in advanced abatement technology? Theory and evidence", Canadian Journal of Economics 49(2), pp.637-662.

[11] Cherniwchan, J., B. R. Copeland and M. S. Taylor (2017), "Trade and the Environment: New Methods, Measurements, and Results," Annual Review of Economics 9(1), pp. 5985.

[12] Copeland, B.R. and M.S. Taylor (1995), "Trade and Transboundary Pollution", American Economic Review (85), pp. 716-737. 
[13] Copeland, B.R. and M.S. Taylor (2003), Trade and the Environment. Theory and Evidence. Princeton University Press, 2003.

[14] Cui, J., H. Lapan and G. Moschini (2016), "Productivity, Export and Environmental Performance: Air Pollutants in the United States", American Journal of Agricultural Economics 98(2), pp.447-467

[15] Copeland, B.R. and M.S. Taylor (2004), "Trade, Growth, and the Environment", Journal of Economic Literature 42(1), pp. 7-71.

[16] Dixit, A. K. and J. E. Stiglitz (1977), "Monopolistic Competition and Optimum Product Diversity", American Economic Review 67(3), 297-308

[17] Ederington, J., A. Levinson and J. Minier (2004), "Trade Liberalization and Pollution Havens", The B.E. Journal of Economic Analysis \& Policy, Berkeley Electronic Press $4(2), 6$.

[18] Felbermayr, G., B. Jung and M. Larch (2013), "Optimal tariffs, retaliation, and the welfare loss from tariff wars in the Melitz model", Journal of International Economics 89(1), pp.13-25.

[19] Forslid, R., T. Okubo and K.H. Ulltveit-Moe (2011), “ Why are Firms that Export cleaner? International Trade and CO2 Emissions", CEPR Discussion Paper No. 8583

[20] Frankel, J. A. and A. K. Rose (2005), "Is Trade Good or Bad for the Environment? Sorting Out the Causality", The Review of Economics and Statistics 87(1), pp.85-91

[21] Girma, S. and A. Hanley (2013), "How Green are Exporters", Kiel Working Paper No. 1887

[22] Grossman, G. M. and A. B. Krueger (1993), "Environmental Impacts of a North American Free Trade Agreement," In P. M. Garber (ed.), The Mexico-U.S. Free Trade Agreement, Cambridge, MA: The MIT Press

[23] Helpman, E., M. J. Melitz, and S. R. Yeaple (2004), "Export versus FDI with Heterogeneous Firms", American Economic Review 94(1), pp. 300-316.

[24] Holladay, S. (2015) "Exporters and the Environment", University of Tennessee, Department of Economics Working Paper, forthcoming in the Canadian Journal of Economics.

[25] Kreickemeier U. and P.M. Richter (2014), "Trade and the Environment: The Role of Firm Heterogeneity", Review of International Economics 22(2), pp. 209-225. 
[26] Levinsohn, J. and A. Petrin (2003), "Estimating production functions using inputs to control for unobservables", Review of Economic Studies 70(2), pp. 317-342.

[27] Levinson, A and M. S. Taylor, (2008), "Unmasking The Pollution Haven Effect," International Economic Review 49(1), pp. 223-254.

[28] Levinson, A. (2009), "Technology, International Trade, and Pollution from US Manufacturing", American Economic Review 99(5), pp. 2177-92.

[29] Levinson, A. (2010), "Offshoring Pollution: Is the US Increasingly Importing Pollution Intensive Production?", Review of Environmental Economics and Policy 4(1), pp. 63-83.

[30] Kreickemeier, U. and P. M. Richter (2014), "Trade and the Environment: The Role of Firm Heterogeneity", Review of International Economics 22(2), pp. 209-225

[31] Melitz, M.J. (2003), "The Impact of Trade on Intra-Industry Reallocations and Aggregate Industry Productivity", Econometrica 71(6), pp 1695-1725.

[32] Naito, T. (2017), "An Asymmetric Melitz model of Trade and Growth", Economics Letters 158, pp.80-83.

[33] Tang, E., F. Liu, J. Zhang and J. Yu (2014), "A model to analyze the environmental policy of resource allocation and pollution control based on firm heterogeneity", Resources Policy 39, pp. 88-91 


\section{A Appendix}

\section{A.1 Optimal Abatement and Productivity Level}

The optimal level of abatement investments is given by:

$$
f_{A}^{D}=\left\{\frac{1}{B}\left(a^{1-\alpha} t^{\alpha}\right)^{\sigma-1} \frac{1}{\alpha \rho(\sigma-1)}\right\}^{\frac{1}{\alpha \rho(\sigma-1)-1}}=\Omega_{D} a^{\frac{(1-\alpha)(\sigma-1)}{\alpha \rho(\sigma-1)-1}}
$$

We differentiate the optimal abatement level with respect to the productivity level:

$$
\frac{\partial f_{A}^{D}}{\partial a}=\frac{(1-\alpha)(\sigma-1)}{\alpha \rho(\sigma-1)-1} \Omega_{D} a^{\frac{(1-\alpha)(\sigma-1)}{\alpha \rho(\sigma-1)-1}-1}<0 .
$$

We observe that abatement investments are increasing in firms' productivity level, provided that

$$
\alpha \rho(\sigma-1)-1<0
$$

i.e. for $\beta>0$. However, we assume that this condition will always hold, since it is a necessary condition for profit maximization

$\frac{\partial^{2} \pi_{D}}{\partial\left(f_{A}^{D}\right)^{2}}=(\alpha \rho(\sigma-1)-1) \alpha \rho(\sigma-1)\left(a^{1-\alpha} t^{\alpha}\right)^{1-\sigma}\left(f_{A}^{D}\right)^{-\alpha \rho(1-\sigma)-2} B<0 \quad \nabla \quad \alpha \rho(\sigma-1)-1<0$.

This implies that abatement has a decreasing marginal effect on firms' profit.

\section{A.2 Condition for $\frac{d f_{A}^{X}}{d \phi}>0$}

Taking logs and differentiating and simplifying gives

$$
\frac{d \log \left(f_{A}^{X}\right)}{d \phi}=\frac{\left(\left(\beta^{3} k-\gamma\right)(1+\phi)^{\frac{1}{\beta}}-\beta^{3} k\right)\left(\frac{f_{D}}{f_{X}}\right)^{\frac{k \beta}{\gamma}-1}+\beta^{3} k}{\beta^{2}(1+\phi) k\left(\left((1+\phi)^{\frac{1}{\beta}}-1\right)\left(\frac{f_{D}}{f_{X}}\right)^{\frac{k \beta}{\gamma}-1}+1\right)}
$$

The sign of this expression is positive when

$$
\left(\left(\beta^{3} k-\gamma\right)(1+\phi)^{\frac{1}{\beta}}-\beta^{3} k\right)\left(\frac{f_{D}}{f_{X}}\right)^{\frac{k \beta}{\gamma}-1}+\beta^{3} k>0
$$

which can be reformulated as 


$$
\frac{\gamma}{k \beta}<\beta^{2}\left(1-\left(1-\left(\frac{f_{D}}{f_{X}}\right)^{\frac{k \beta}{\gamma}-1}\right)(1+\phi)^{-\frac{1}{\beta}}\right)
$$

\section{A.3 Proof of Proposition $9\left(\frac{d\left(e^{x} / x\right)}{d \phi}>0\right)$}

Differentiation of (33) w.r.t. $\phi$ and simplifying gives

$$
\begin{gathered}
\frac{d\left(e^{x} / x\right)}{d \phi}=\alpha^{2} \kappa \rho\left(\frac{\beta}{f_{D}(1-\beta)}\right)^{\alpha \rho}(1+\phi)^{-\frac{\alpha \rho}{\beta}} \\
\frac{\left(\frac{\left(\frac{k \beta}{\gamma}-1\right) f_{e}}{f_{D}\left(\left((1+\phi)^{\frac{1}{\beta}}-1\right)^{\frac{k \beta}{\gamma}}\left(\frac{f_{D}}{f_{X}}\right)^{\frac{k \beta}{\gamma}-1}+1\right)}\right)^{-\frac{\alpha \rho \gamma}{k \beta}}\left(\left((1+\phi)^{\frac{1}{\beta}}-1\right)^{\frac{k \beta}{\gamma}}\left(\frac{f_{D}}{f_{X}}\right)^{\frac{k \beta}{\gamma}-1}-(1+\phi)^{\frac{1}{\beta}}+1\right)}{\beta\left(\left((1+\phi)^{\frac{1}{\beta}}-1\right)^{\frac{k \beta}{\gamma}}\left(\frac{f_{D}}{f_{X}}\right)^{\frac{k \beta}{\gamma}-1}+1\right)(1+\phi)\left((1+\phi)^{\frac{1}{\beta}}-1\right)} t^{-(1-\alpha)} a_{i}^{\frac{1-\alpha}{\beta}}
\end{gathered}
$$

The sign of this expression depends on the term $\left(\left((1+\phi)^{\frac{1}{\beta}}-1\right)^{\frac{k \beta}{\gamma}}\left(\frac{f_{D}}{f_{X}}\right)^{\frac{k \beta}{\gamma}-1}-(1+\phi)^{\frac{1}{\beta}}+1\right)$ in the numerator given that $\frac{k \beta}{\gamma}>1,0<\phi<1$, and $0<\beta<1$. Rearranging this term gives

$$
\frac{f_{X}}{f_{D}}\left(\left(\left((1+\phi)^{\frac{1}{\beta}}-1\right) \frac{f_{D}}{f_{X}}\right)^{\frac{k \beta}{\gamma}}-\left((1+\phi)^{\frac{1}{\beta}}-1\right) \frac{f_{D}}{f_{X}}\right)<0
$$

given that $\left((1+\phi)^{\frac{1}{\beta}}-1\right) \frac{f_{D}}{f_{X}}<1$, and that $\frac{k \beta}{\gamma}>1$.

Thus, we have that

$$
\frac{d\left(e^{x} / x\right)}{d \phi}<0
$$




\section{A.4 NOT FOR PUBLICATION, Solving for Symmetric countries}

Assume symmetric taxes and labor supply $(L)$ so that $B=B^{*}$.

\section{A.4.1 Cut-off productivities}

Optimal abatement investments are derived in Section 3.5 in the main text:

$$
\begin{gathered}
f_{A}^{D}=\left\{\frac{1}{B}\left(a^{1-\alpha} t^{\alpha}\right)^{\sigma-1} \frac{1}{1-\beta}\right\}^{-\frac{1}{\beta}} \\
f_{A}^{X}=\left\{\frac{1}{(B+\phi B)}\left(a^{1-\alpha} t^{\alpha}\right)^{\sigma-1} \frac{1}{1-\beta}\right\}^{-\frac{1}{\beta}}
\end{gathered}
$$

where $B \equiv \frac{\kappa^{1-\sigma} \sigma^{-\sigma}(\sigma-1)^{\sigma-1} \mu L}{P^{1-\sigma}}$ is exogenous to the firm. Now calculate relative abatement investments:

$$
\frac{f_{A}^{X}}{f_{A}^{D}}=\left\{\frac{1}{(1+\phi)}\right\}^{-\frac{1}{\beta}}
$$

The cut-off conditions are found in the main text text in Section 3.4 and are given by:

$$
\begin{gathered}
\left(a_{D}^{1-\alpha}\left(\frac{t}{\left(f_{A}^{D}\right)^{\rho}}\right)^{\alpha}\right)^{1-\sigma} B=f_{D}+f_{A}^{D} \\
\left(a_{X}^{1-\alpha}\left(\frac{t}{\left(f_{A}^{X}\right)^{\rho}}\right)^{\alpha}\right)^{1-\sigma} \phi B+\left(a_{X}^{1-\alpha}\left(\frac{t}{\left(f_{A}^{X}\right)^{\rho}}\right)^{\alpha}\right)^{1-\sigma} B-\left(a_{X}^{1-\alpha}\left(\frac{t}{\left(f_{A}^{D}\right)^{\rho}}\right)^{\alpha}\right)^{1-\sigma} B=f_{X}+f_{A}^{X}-f_{A}^{D} .
\end{gathered}
$$

Substituting (49) into (52) gives

$$
\left(a_{D}^{1-\alpha}\left(\frac{t}{\left\{\frac{1}{B}\left(a_{D}^{1-\alpha} t^{\alpha}\right)^{\sigma-1} \frac{1}{1-\beta}\right\}^{-\frac{\rho}{\beta}}}\right)^{\alpha}\right)^{1-\sigma} B=f_{D}+\left\{\frac{1}{B}\left(a_{D}^{1-\alpha} t^{\alpha}\right)^{\sigma-1} \frac{1}{1-\beta}\right\}^{-\frac{1}{\beta}} .
$$

Simplifying and rewriting (54) gives us an expression for $B$ as a function of $a_{D}$ and $t$ :

$$
B=\frac{f_{D}^{\beta} a_{D}^{\gamma} t^{\alpha(\sigma-1)}}{\left(\left(\frac{1}{1-\beta}\right)^{\frac{\rho}{\beta} \alpha(1-\sigma)}-\left(\frac{1}{1-\beta}\right)^{-\frac{1}{\beta}}\right)^{\beta}}=\frac{f_{D}^{\beta} a_{D}^{\gamma} t^{\alpha(\sigma-1)}}{\varkappa^{\beta}}
$$

where $\varkappa \equiv\left(\frac{1}{1-\beta}\right)^{\frac{\rho}{\beta} \alpha(1-\sigma)}-\left\{\frac{1}{1-\beta}\right\}^{-\frac{1}{\beta}}=(1-\beta)^{\frac{1-\beta}{\beta}}-\{1-\beta\}^{\frac{1}{\beta}}>0$. 
Next we substitute (49) and (50) into (53) to get

$$
\begin{aligned}
& \left(a_{X}^{1-\alpha}\left(\frac{t}{\left\{\frac{1}{B(1+\phi)}\left(a_{X}^{1-\alpha} t^{\alpha}\right)^{\sigma-1} \frac{1}{1-\beta}\right\}^{-\frac{\rho}{\beta}}}\right)^{\alpha}\right)^{1-\sigma} B(\phi+1) \\
& -\left(a_{X}^{1-\alpha}\left(\frac{t}{\left\{\frac{1}{B}\left(a_{X}^{1-\alpha} t^{\alpha}\right)^{\sigma-1} \frac{1}{1-\beta}\right\}^{-\frac{\rho}{\beta}}}\right)^{\alpha}\right)^{1-\sigma} B \\
& =f_{X}+\left\{\frac{1}{B(1+\phi)}\left(a_{X}^{1-\alpha} t^{\alpha}\right)^{\sigma-1} \frac{1}{1-\beta}\right\}^{-\frac{1}{\beta}}-\left\{\frac{1}{B}\left(a_{X}^{1-\alpha} t^{\alpha}\right)^{\sigma-1} \frac{1}{1-\beta}\right\}^{-\frac{1}{\beta}},
\end{aligned}
$$

which we can simplify and rewrite so as to get $B$ as a function of $a_{x}$ and $t$ :

$$
B=\frac{a_{X}^{\gamma} t^{\alpha(\sigma-1)} f_{X}^{\beta}}{\left((1+\phi)^{\frac{1}{\beta}}-1\right)^{\beta} \varkappa^{\beta}} .
$$

Using (55) and (57) gives the relative cut-off condition ratio:

$$
\frac{a_{X}^{\gamma}}{a_{D}^{\gamma}}=\left((\phi+1)^{\frac{1}{\beta}}-1\right)^{\beta} \frac{f_{D}^{\beta}}{f_{X}^{\beta}} .
$$

Next solve the free-entry condition

$$
\begin{aligned}
f_{E} & =\int_{0}^{a_{X}}\left(\left(a^{1-\alpha}\left(\frac{t}{\left(f_{A}^{X}\right)^{\rho}}\right)^{\alpha}\right)^{1-\sigma} B(1+\phi)-f_{D}-f_{X}-f_{A}^{X}\right) d G(a) \\
& +\int_{a_{X}}^{a_{D}}\left[\left(a^{1-\alpha}\left(\frac{t}{\left(f_{A}^{D}\right)^{\rho}}\right)^{\alpha}\right)^{1-\sigma} B-f_{D}-f_{A}^{D}\right] d G(a) .
\end{aligned}
$$

Using (19) and (20) to substitute, we get

$$
\begin{aligned}
& f_{E}+a_{X}^{k}\left(f_{D}+f_{X}\right)+\left(a_{D}^{k}-a_{X}^{k}\right) f_{D} \\
& =B^{\frac{1}{\beta}}(1+\phi)^{\frac{1}{\beta}} t^{-\frac{\alpha(\sigma-1)}{\beta}} \varkappa k \int_{0}^{a_{X}} a^{-\frac{\gamma}{\beta}} a^{k-1} d a+B^{\frac{1}{\beta}} t^{-\frac{\alpha(\sigma-1)}{\beta}} \varkappa k \int_{a_{X}}^{a_{D}} a^{-\frac{\gamma}{\beta}} a^{k-1} d a .
\end{aligned}
$$

Solving the integral, we get 


$$
\begin{aligned}
& f_{E}+a_{X}^{k}\left(f_{D}+f_{X}\right)+\left(a_{D}^{k}-a_{X}^{k}\right) f_{D} \\
& =B^{\frac{1}{\beta}}(1+\phi)^{\frac{1}{\beta}} t^{-\frac{\alpha(\sigma-1)}{\beta}} \varkappa \frac{k \beta}{k \beta-\gamma} a_{X}^{k-\frac{\gamma}{\beta}} \\
& +B^{\frac{1}{\beta}} t^{-\frac{\alpha(\sigma-1)}{\beta}} \varkappa \frac{k \beta}{k \beta-\gamma}\left(a_{D}^{k-\frac{\gamma}{\beta}}-a_{X}^{k-\frac{\gamma}{\beta}}\right)
\end{aligned}
$$

and substituting in the solutions for $B,(55)$ and (57):

$$
\begin{aligned}
& f_{E}+a_{X}^{k}\left(f_{D}+f_{X}\right)+\left(a_{D}^{k}-a_{X}^{k}\right) f_{D} \\
& =\left(\frac{a_{X}^{\gamma} t^{\alpha(\sigma-1)} f_{X}^{\beta}}{\left((1+\phi)^{\frac{1}{\beta}}-1\right)^{\beta} \varkappa^{\beta}}\right)^{\frac{1}{\beta}}(1+\phi)^{\frac{1}{\beta}} t^{-\frac{\alpha(\sigma-1)}{\beta}} \varkappa \frac{k \beta}{k \beta-\gamma} a_{X}^{k-\frac{\gamma}{\beta}} \\
& +\left(\frac{f_{D}^{\beta} a_{D}^{\gamma} t^{\alpha(\sigma-1)}}{\varkappa^{\beta}}\right)^{\frac{1}{\beta}} t^{-\frac{\alpha(\sigma-1)}{\beta}} \varkappa \frac{k \beta}{k \beta-\gamma} a_{D}^{k-\frac{\gamma}{\beta}} \\
& -\left(\frac{a_{X}^{\gamma} t^{\alpha(\sigma-1)} f_{X}^{\beta}}{\left((1+\phi)^{\frac{1}{\beta}}-1\right)^{\beta} \varkappa^{\beta}}\right)^{\frac{1}{\beta}} t^{-\frac{\alpha(\sigma-1)}{\beta}} \varkappa \frac{k \beta}{k \beta-\gamma} a_{X}^{k-\frac{\gamma}{\beta}}
\end{aligned}
$$

gives

$$
f_{E}+a_{X}^{k} f_{X}\left(-\frac{\gamma}{k \beta-\gamma}\right)+a_{D}^{k} f_{D}\left(-\frac{\gamma}{k \beta-\gamma}\right)=0 .
$$

Now substitute out $a_{X}$ using (58) to get

$$
\begin{gathered}
f_{E}+a_{D}^{k}\left((\phi+1)^{\frac{1}{\beta}}-1\right)^{\frac{k \beta}{\gamma}} \frac{f_{D}^{\frac{k \beta}{\gamma}}}{f_{X}^{\frac{k \beta}{\gamma}}} f_{X}\left(\frac{-\gamma}{k \beta-\gamma}\right) \\
+a_{D}^{k} f_{D}\left(\frac{-\gamma}{k \beta-\gamma}\right)=0
\end{gathered}
$$

and rewrite this to get an expression for $a_{D}^{k}$, which gives the equilibrium cut-off productivity for domestic producers

$$
\bar{a}_{D}^{k}=\frac{f_{E}}{\left(\frac{\gamma}{k \beta-\gamma}\right) f_{D}\left(\left((\phi+1)^{\frac{1}{\beta}}-1\right)^{\frac{k \beta}{\gamma}} f_{D}^{\frac{k \beta}{\gamma}-1} f_{X}^{1-\frac{k \beta}{\gamma}}+1\right)} .
$$

Using (58) gives the corresponding equilibrium cut-off productivity for exporters in the 
symmetric case:

$$
\bar{a}_{X}^{k}=\frac{f_{E}}{\left(\frac{\gamma}{k \beta-\gamma}\right) f_{X}\left(1+\frac{1}{\left((\phi+1)^{\frac{1}{\beta}}-1\right)^{\frac{k \beta}{\gamma}} f_{X}^{1-\frac{k \beta}{\gamma}} f_{D}^{\frac{k \beta}{\gamma}}-1}\right)} .
$$

\section{A.4.2 Calculate the price index $(P)$}

We now calculate the price index for the symmetric case. We have that $B \equiv \frac{\kappa^{1-\sigma} \sigma^{-\sigma}(\sigma-1)^{\sigma-1} \mu L_{j}}{P_{j}^{1-\sigma}}=$ $\frac{\varsigma \mu L_{j}}{P_{j}^{1-\sigma}}$, where $\varsigma \equiv \kappa^{1-\sigma} \sigma^{-\sigma}(\sigma-1)^{\sigma-1}$. According to (55), we have that

$$
B=\frac{f_{D}^{\beta} a_{D}^{\gamma} t^{\alpha(\sigma-1)}}{\varkappa^{\beta}}=\frac{\varsigma \mu L_{j}}{P_{j}^{1-\sigma}}
$$

which can be rewritten as

$$
P=\left(\frac{\varsigma \mu L_{j} \varkappa^{\beta}}{f_{D}^{\beta} a_{D}^{\gamma} t^{\alpha(\sigma-1)}}\right)^{\frac{1}{1-\sigma}}=\left(\frac{\varkappa}{f_{D}}\right)^{\frac{\beta}{1-\sigma}}(\varsigma \mu)^{\frac{1}{1-\sigma}} L_{j}^{\frac{1}{1-\sigma}} a_{D}^{(1-\alpha)} t^{\alpha},
$$

and substituting in for $a_{D}^{k}$ using (63) gives the price index

$$
\begin{aligned}
\bar{P} & =\left(\frac{\varkappa}{f_{D}}\right)^{\frac{\beta}{1-\sigma}}(\varsigma \mu)^{\frac{1}{1-\sigma}} L_{j}^{\frac{1}{1-\sigma}} t^{\alpha} . \\
& \left(\frac{f_{E}}{\left.\left(\frac{\gamma}{k \beta-\gamma}\right) f_{D}\left((\phi+1)^{\frac{1}{\beta}}-1\right)^{\frac{k \beta}{\gamma}} f_{D}^{\frac{k \beta}{\gamma}-1} f_{X}^{1-\frac{k \beta}{\gamma}}+1\right)}\right)^{\frac{(1-\alpha)}{k}} .
\end{aligned}
$$

\section{A.4.3 Calculating the number of firms in the symmetric case $\left(n=n^{*}\right)$}

The price of an individual variety of a non-exporter is given by (from the main text):

$$
p=\frac{\sigma}{\sigma-1} \kappa\left(\frac{t}{f_{A}^{\rho}}\right)^{\alpha} a^{(1-\alpha)}=\frac{\sigma}{\sigma-1} \kappa t^{\alpha}\left(\bar{f}_{A}^{D}\right)^{\rho \alpha} a^{(1-\alpha)} .
$$

After substituting in $\bar{f}_{A}^{D}$ from (19), we get the non-export price

$$
p=\frac{\sigma}{\sigma-1} \kappa B^{-\frac{\rho \alpha}{\beta}}\left(\frac{1}{1-\beta}\right)^{\frac{\rho \alpha}{\beta}} t^{\frac{(1-\beta) \alpha}{\beta}+\alpha} a^{(1-\alpha)+\frac{(1-\alpha)(1-\beta)}{\beta}}=\frac{\sigma}{\sigma-1} \kappa B^{-\frac{\rho \alpha}{\beta}}\left(\frac{1}{1-\beta}\right)^{\frac{\rho \alpha}{\beta}} t^{\frac{\alpha}{\beta}} a^{\frac{(1-\alpha)}{\beta}} .
$$


The price of exporters is derived in the same fashion

$$
\begin{aligned}
p^{*} & =\frac{\sigma}{\sigma-1} \kappa(B+\phi B)^{-\frac{\rho \alpha}{\beta}}\left(\frac{1}{1-\beta}\right)^{\frac{\rho \alpha}{\beta}} t^{\frac{(1-\beta) \alpha}{\beta}+\alpha} a^{(1-\alpha)+\frac{(1-\alpha)(1-\beta)}{\beta}} \\
& =\frac{\sigma}{\sigma-1} \kappa(B+\phi B)^{-\frac{\rho \alpha}{\beta}}\left(\frac{1}{1-\beta}\right)^{\frac{\rho \alpha}{\beta}} t^{\frac{\alpha}{\beta}} a^{\frac{(1-\alpha)}{\beta}} .
\end{aligned}
$$

Next the price index is given by

$$
\Delta=P^{1-\sigma}=n \int_{o}^{a_{X}} p_{X}^{(1-\sigma)} d G+n \int_{a_{X}}^{a_{D}} p_{D}^{(1-\sigma)} d G+\varphi n^{*} \int_{o}^{a_{X}} p_{X}^{* 1-\sigma} d G
$$

Substitute in prices solving the integrals and simplifying gives

$\Delta=\left(\frac{\sigma}{\sigma-1} \kappa\right)^{(1-\sigma)} \Upsilon\left(\begin{array}{c}n\left(B+\phi B^{*}\right)^{\frac{1-\beta}{\beta}} t^{\frac{\alpha(1-\sigma)}{\beta}} a_{X}^{-\frac{\gamma}{\beta}}\left(\frac{a_{X}}{a_{D}}\right)^{k}+n B^{\frac{1-\beta}{\beta}} t^{\frac{\alpha(1-\sigma)}{\beta}}\left(a_{D}^{-\frac{\gamma}{\beta}}-a_{X}^{-\frac{\gamma}{\beta}}\left(\frac{a_{X}}{a_{D}}\right)^{k}\right) \\ +\phi n^{*}\left(\phi B+B^{*}\right)^{\frac{1-\beta}{\beta}} t^{* \frac{\alpha(1-\sigma)}{\beta}} a_{X}^{*-\frac{\gamma}{\beta}}\left(\frac{a_{X}^{*}}{a_{D}}\right)^{k}\end{array}\right)$

where $\Upsilon \equiv\{1-\beta\}^{\frac{1-\beta}{\beta}} \frac{k \beta}{k \beta-\gamma}, \gamma \equiv(\sigma-1)(1-\alpha)>0$ and $\beta \equiv 1-\alpha \rho(\sigma-1)>0$.

Now calculate $n$

The definition of $\mathrm{B}$

$$
B=\frac{\kappa^{1-\sigma} \sigma^{-\sigma}(\sigma-1)^{\sigma-1} \mu L_{j}}{P_{j}^{1-\sigma}}
$$

gives

$$
P_{j}^{1-\sigma}=\Delta_{j}=\frac{\kappa^{1-\sigma} \sigma^{-\sigma}(\sigma-1)^{\sigma-1} \mu L_{j}}{B_{j}}
$$

From (55)

$$
B=\frac{f_{D}^{\beta} a_{D}^{\gamma} t^{\alpha(\sigma-1)}}{\varkappa^{\beta}}
$$

substitute B gives

$$
\Delta_{j}=\frac{\kappa^{1-\sigma} \sigma^{-\sigma}(\sigma-1)^{\sigma-1} \mu L_{j}}{\frac{f_{a^{\beta} \alpha_{j}^{\gamma} t_{j}^{\alpha(\sigma-1)}}^{\varkappa^{\beta}}}{\varkappa^{\beta}}}=\frac{\varkappa^{\beta} \kappa^{1-\sigma} \sigma^{-\sigma}(\sigma-1)^{\sigma-1} \mu L_{j}}{f_{D}^{\beta} a_{D j}^{\gamma} t_{j}^{\alpha(\sigma-1)}}
$$

use (69) 
$\frac{\varkappa^{\beta} \kappa^{1-\sigma} \sigma^{-\sigma}(\sigma-1)^{\sigma-1} \mu L_{j}}{f_{D}^{\beta} a_{D j}^{\gamma} t_{j}^{\alpha(\sigma-1)}}=$
$\left(\frac{\sigma}{\sigma-1} \kappa\right)^{(1-\sigma)} \Upsilon\left(\begin{array}{r}n\left(B+\phi B^{*}\right)^{\frac{1-\beta}{\beta}} t^{\frac{\alpha(1-\sigma)}{\beta}} a_{X}^{-\frac{\gamma}{\beta}}\left(\frac{a_{X}}{a_{D}}\right)^{k}+n B^{\frac{1-\beta}{\beta}} t^{\frac{\alpha(1-\sigma)}{\beta}}\left(a_{D}^{-\frac{\gamma}{\beta}}-a_{X}^{-\frac{\gamma}{\beta}}\left(\frac{a_{X}}{a_{D}}\right)^{k}\right) \\ +\phi n^{*}\left(\phi B+B^{*}\right)^{\frac{1-\beta}{\beta}} t^{* \frac{\alpha(1-\sigma)}{\beta}} a_{X}^{*-\frac{\gamma}{\beta}}\left(\frac{a_{X}^{*}}{a_{D}}\right)^{k}\end{array}\right)$

With symmetric countries $B=B^{*}$

$$
\frac{\varkappa^{\beta} \mu L_{j}}{f_{D}^{\beta} a_{D j}^{\gamma} t_{j}^{\alpha(\sigma-1)}}=\sigma \Upsilon B^{\frac{1-\beta}{\beta}}\left(\begin{array}{c}
n(1+\phi)^{\frac{1-\beta}{\beta}} t^{\frac{\alpha(1-\sigma)}{\beta}} a_{X}^{-\frac{\gamma}{\beta}}\left(\frac{a_{X}}{a_{D}}\right)^{k}+n t^{\frac{\alpha(1-\sigma)}{\beta}}\left(a_{D}^{-\frac{\gamma}{\beta}}-a_{X}^{-\frac{\gamma}{\beta}}\left(\frac{a_{X}}{a_{D}}\right)^{k}\right. \\
+\phi n^{*}(\phi+1)^{\frac{1-\beta}{\beta}} t^{* \frac{\alpha(1-\sigma)}{\beta}} a_{X}^{*-\frac{\gamma}{\beta}}\left(\frac{a_{X}^{*}}{a_{D}}\right)^{k}
\end{array}\right)
$$

Substitute $B$ from (70) and simplification gives

$\mu L_{j}=\sigma \Upsilon f_{D} a_{D}^{\frac{\gamma}{\beta}} t^{\frac{\alpha(\sigma-1)}{\beta}} \varkappa^{-1}\left(\begin{array}{c}n(1+\phi)^{\frac{1-\beta}{\beta}} t^{\frac{\alpha(1-\sigma)}{\beta}} a_{X}^{-\frac{\gamma}{\beta}}\left(\frac{a_{X}}{a_{D}}\right)^{k}+n t^{\frac{\alpha(1-\sigma)}{\beta}}\left(a_{D}^{-\frac{\gamma}{\beta}}-a_{X}^{-\frac{\gamma}{\beta}}\left(\frac{a_{X}}{a_{D}}\right)^{k}\right) \\ +\phi n^{*}(\phi+1)^{\frac{1-\beta}{\beta}} t^{* \frac{\alpha(1-\sigma)}{\beta}} a_{X}^{*-\frac{\gamma}{\beta}}\left(\frac{a_{X}^{*}}{a_{D}}\right)^{k}\end{array}\right)$

With symmetry, except for $L$ and $L^{*}$, we have $t=t^{*}, B=B^{*}$ and that $a_{D}=a_{D}^{*}$, which gives

$$
\mu L_{j}=\sigma \Upsilon f_{D} \varkappa^{-1}\left(\begin{array}{c}
n(1+\phi)^{\frac{1-\beta}{\beta}}\left(\frac{a_{X}}{a_{D}}\right)^{k-\frac{\gamma}{\beta}}+n\left(1-\left(\frac{a_{X}}{a_{D}}\right)^{k-\frac{\gamma}{\beta}}\right) \\
+\phi n^{*}(\phi+1)^{\frac{1-\beta}{\beta}}\left(\frac{a_{X}^{*}}{a_{D}}\right)^{k-\frac{\gamma}{\beta}}
\end{array}\right)
$$

now

$$
\left(\frac{a_{X}}{a_{D}}\right)=\left((\phi+1)^{\frac{1}{\beta}}-1\right)^{\frac{\beta}{\gamma}}\left(\frac{f_{D}}{f_{X}}\right)^{\frac{\beta}{\gamma}}
$$

Subst into (75) and solve for $n$ gives

$$
n=\frac{\mu L(k \beta-\gamma)}{f_{D} \sigma k\left(\left((\phi+1)^{\frac{1}{\beta}}-1\right)\left(\frac{f_{D}}{f_{X}}\right)\right)^{\frac{k \beta}{\gamma}-1}\left((1+\phi)^{\frac{1-\beta}{\beta}}-1+\left(\left((\phi+1)^{\frac{1}{\beta}}-1\right)\left(\frac{f_{D}}{f_{X}}\right)\right)^{1-\frac{k \beta}{\gamma}}+\phi \frac{n^{*}}{n}(\phi+1)^{\frac{1-\beta}{\beta}}\right)}
$$




$$
n^{*}=\frac{\mu L^{*}(k \beta-\gamma)}{f_{D} \sigma k\left(\left((\phi+1)^{\frac{1}{\beta}}-1\right)\left(\frac{f_{D}}{f_{X}}\right)\right)^{\frac{k \beta}{\gamma}-1}\left((1+\phi)^{\frac{1-\beta}{\beta}}-1+\left(\left((\phi+1)^{\frac{1}{\beta}}-1\right)\left(\frac{f_{D}}{f_{X}}\right)\right)^{1-\frac{k \beta}{\gamma}}+\phi \frac{n}{n^{*}}(\phi+1)^{\frac{1-\beta}{\beta}}\right)}
$$

calculate ratio

$$
\frac{n}{n^{*}}=\frac{L\left((1+\phi)^{\frac{1-\beta}{\beta}}-1+\left(\left((\phi+1)^{\frac{1}{\beta}}-1\right)\left(\frac{f_{D}}{f_{X}}\right)\right)^{1-\frac{k \beta}{\gamma}}+\phi \frac{n}{n^{*}}(\phi+1)^{\frac{1-\beta}{\beta}}\right)}{L^{*}\left((1+\phi)^{\frac{1-\beta}{\beta}}-1+\left(\left((\phi+1)^{\frac{1}{\beta}}-1\right)\left(\frac{f_{D}}{f_{X}}\right)\right)^{1-\frac{k \beta}{\gamma}}+\phi \frac{n^{*}}{n}(\phi+1)^{\frac{1-\beta}{\beta}}\right)}
$$

isolate $\frac{n}{n^{*}}$ and substitute into $n$. Simplification under symmetry $L=L^{*}, n=n^{*}$ gives

$$
n=\frac{\mu L_{j}(k \beta-\gamma)}{f_{D} \sigma k\left(\left((1+\phi)^{\frac{1}{\beta}}-1\right)^{\frac{k \beta}{\gamma}}\left(\frac{f_{D}}{f_{X}}\right)^{\frac{k \beta}{\gamma}-1}+1\right)}
$$

\section{A.4.4 Non-exporter emissions}

Emission intensity is given by (from the main text):

$$
\frac{e}{x}=\alpha \kappa t^{\alpha-1} f_{A}^{-\rho \alpha} a^{1-\alpha}
$$

Substituting optimal abatement investments from (49)

$$
f_{A}^{D}=\left\{\frac{1}{B}\left(a^{1-\alpha} t^{\alpha}\right)^{\sigma-1} \frac{1}{\alpha \rho(\sigma-1)}\right\}^{\frac{1}{\alpha \rho(\sigma-1)-1}}
$$

gives

$$
e^{D}=\alpha \kappa t^{\frac{\alpha-\beta}{\beta}} B^{-\frac{\rho \alpha}{\beta}}\left(\frac{1}{1-\beta}\right)^{\frac{\rho \alpha}{\beta}} a^{\frac{(1-\alpha)}{\beta}} x
$$

First, derive the equilibrium emission intensity of non-exporters in the symmetric case. Substituting for $B$ from (55) gives

$$
e^{D}=\alpha \kappa t^{\frac{\alpha-\beta}{\beta}-\frac{\alpha(1-\beta)}{\beta}} f_{D}^{-\rho \alpha} \varkappa^{\rho \alpha} a_{D}^{-\frac{(1-\beta)}{\beta}(1-\alpha)}\left(\frac{1}{1-\beta}\right)^{\frac{\rho \alpha}{\beta}} a^{\frac{(1-\alpha)}{\beta}} x
$$

with $\varsigma \equiv \kappa^{1-\sigma} \sigma^{-\sigma}(\sigma-1)^{\sigma-1}, \varkappa \equiv(1-\beta)^{\frac{1-\beta}{\beta}}-(1-\beta)^{\frac{1}{\beta}}$, and $\beta=1-\alpha \rho(\sigma-1)$. We rewrite so that

$$
\frac{e^{D}}{x}=\alpha \kappa t^{\frac{\alpha-\beta}{\beta}-\frac{\alpha(1-\beta)}{\beta}} f_{D}^{-\rho \alpha} a_{D}^{-\frac{(1-\beta)}{\beta}(1-\alpha)}\left((1-\beta)^{\frac{1-\beta}{\beta}}-(1-\beta)^{\frac{1}{\beta}}\right)^{\rho \alpha}\left(\frac{1}{1-\beta}\right)^{\frac{\rho \alpha}{\beta}} a^{\frac{(1-\alpha)}{\beta}}
$$


and simplify to get

$$
\frac{\bar{e}^{D}}{x}=\alpha \kappa t^{\alpha-1} f_{D}^{-\rho \alpha} a_{D}^{-\frac{(1-\beta)}{\beta}(1-\alpha)}\left(\frac{\beta}{1-\beta}\right)^{\rho \alpha} a^{\frac{(1-\alpha)}{\beta}}
$$

For exporters, we can calculate the equilibrium emission intensity in a similar fashion:

$$
\frac{\bar{e}^{X}}{x}=\alpha \kappa t^{\alpha-1} f_{D}^{-\rho \alpha}(1+\phi)^{-\frac{\rho \alpha}{\beta}} a_{D}^{-\frac{(1-\beta)}{\beta}(1-\alpha)}\left(\frac{\beta}{1-\beta}\right)^{\rho \alpha} a^{\frac{(1-\alpha)}{\beta}}
$$

Next, we calculate the level of total emissions. We start with non-exporters. The quantity sold domestically is:

$$
x=\frac{p^{-\sigma} \mu L}{P^{1-\sigma}}
$$

The non-export price

$$
p=\frac{\sigma}{\sigma-1} \kappa B^{-\frac{\rho \alpha}{\beta}}\left\{\frac{1}{1-\beta}\right\}^{\frac{\rho \alpha}{\beta}} t^{\frac{(1-\beta) \alpha}{\beta}+\alpha} a^{(1-\alpha)+\frac{(1-\alpha)(1-\beta)}{\beta}}=\frac{\sigma}{\sigma-1} \kappa B^{-\frac{\rho \alpha}{\beta}}\left\{\frac{1}{1-\beta}\right\}^{\frac{\rho \alpha}{\beta}} t^{\frac{\alpha}{\beta}} a^{\frac{(1-\alpha)}{\beta}}
$$

which gives

$$
x=\frac{\left(\frac{\sigma}{\sigma-1}\right)^{-\sigma} \kappa^{-\sigma} \mu L B^{\frac{\sigma \rho \alpha}{\beta}}\left(\left\{\frac{1}{1-\beta}\right\}^{\frac{\rho \alpha}{\beta}} t^{\frac{\alpha}{\beta}} a^{\frac{(1-\alpha)}{\beta}}\right)^{-\sigma}}{P^{1-\sigma}} .
$$

Since $B \equiv \frac{\kappa^{1-\sigma} \sigma^{-\sigma}(\sigma-1)^{\sigma-1} \mu L_{j}}{P_{j}^{1-\sigma}}$, this implies that $\frac{(\sigma-1) B}{\kappa}=\frac{\kappa^{-\sigma} \sigma^{-\sigma}(\sigma-1)^{\sigma} \mu L_{j}}{P_{j}^{1-\sigma}}$. which we can use to substitute into $(80)$, to get

$$
x=\frac{(\sigma-1)}{\kappa} B^{\frac{\sigma \rho \alpha}{\beta}+1} t^{-\frac{\sigma \alpha}{\beta}} a^{-\frac{\sigma(1-\alpha)}{\beta}}\left\{\frac{1}{1-\beta}\right\}^{-\frac{\sigma \rho \alpha}{\beta}}
$$

which we in turn substitute into (77). This gives

$$
e^{D}=\alpha \kappa t^{\frac{\alpha-\beta}{\beta}} B^{-\frac{\rho \alpha}{\beta}}\left(\frac{1}{1-\beta}\right)^{\frac{\rho \alpha}{\beta}} a^{\frac{(1-\alpha)}{\beta}} \frac{(\sigma-1)}{\kappa} B^{\frac{\sigma \rho \alpha}{\beta}+1} t^{-\frac{\sigma \alpha}{\beta}} a^{-\frac{\sigma(1-\alpha)}{\beta}}\left\{\frac{1}{1-\beta}\right\}^{-\frac{\sigma \rho \alpha}{\beta}}
$$

which can be simplified to get

$$
e^{D}=\alpha t^{\frac{\alpha(1-\sigma)-\beta}{\beta}}\left(\frac{1}{1-\beta}\right)^{\frac{\beta-1}{\beta}} a^{-\frac{\gamma}{\beta}}(\sigma-1) B^{\frac{1}{\beta}} .
$$

Use (55) to substitute for $B$ and simplify to get 


$$
\begin{gathered}
e^{D}=\alpha t^{\frac{\alpha(1-\sigma)-\beta}{\beta}}\left(\frac{1}{1-\beta}\right)^{\frac{\beta-1}{\beta}} a^{-\frac{\gamma}{\beta}}(\sigma-1)\left(\frac{f_{D}^{\beta} a_{D}^{\gamma} t^{\alpha(\sigma-1)}}{\varkappa^{\beta}}\right)^{\frac{1}{\beta}} . \\
e^{D}=\alpha t^{-1} \frac{1}{\beta} a^{-\frac{\gamma}{\beta}}(\sigma-1) f_{D} a_{D}^{\frac{\gamma}{\beta}} .
\end{gathered}
$$

substitute $a_{D}$

$$
e^{D}=\alpha t^{-1} \frac{1}{\beta}(\sigma-1) f_{D}\left(\frac{f_{E}}{\left(\frac{\gamma}{k \beta-\gamma}\right) f_{D}\left(\left((\phi+1)^{\frac{1}{\beta}}-1\right)^{\frac{k \beta}{\gamma}} f_{D}^{\frac{k \beta}{\gamma}-1} f_{X}^{1-\frac{k \beta}{\gamma}}+1\right)}\right)^{\frac{\gamma}{k \beta}} a^{-\frac{\gamma}{\beta}}
$$

Total emissions of non-exporters are (from the main text):

$$
E_{D}=n \int{ }_{a_{X}}^{a_{D}} e^{D} d G\left(a \mid a_{D}\right)
$$

Solving the integral, conditional on entry gives:

$$
E_{D}=n \alpha t^{\frac{\alpha(1-\sigma)-\beta}{\beta}}\left(\frac{1}{1-\beta}\right)^{\frac{\beta-1}{\beta}}(\sigma-1) B^{\frac{1}{\beta}} \frac{k \beta}{k \beta-\gamma} a_{D}^{-\frac{\gamma}{\beta}}\left(1-\left(\frac{a_{X}}{a_{D}}\right)^{-\frac{\gamma}{\beta}+k}\right)
$$

while from (58) we have that $a_{X} / a_{D}=\left((\phi+1)^{\frac{1}{\beta}}-1\right)^{\frac{\beta}{\gamma}}\left(\frac{f_{D}}{f_{X}}\right)^{\frac{\beta}{\gamma}}$. Substitute this

$$
E_{D}=n \alpha t^{\frac{\alpha(1-\sigma)-\beta}{\beta}}\left(\frac{1}{1-\beta}\right)^{\frac{\beta-1}{\beta}}(\sigma-1) B^{\frac{1}{\beta}} \frac{k \beta}{k \beta-\gamma} a_{D}^{-\frac{\gamma}{\beta}}\left(1-\left(\left((\phi+1)^{\frac{1}{\beta}}-1\right)^{\frac{\beta}{\gamma}}\left(\frac{f_{D}}{f_{X}}\right)^{\frac{\beta}{\gamma}}\right)^{-\frac{\gamma}{\beta}+k}\right)
$$

We use (55) to substitute for $B$ and simplify to get

$$
\begin{gathered}
E_{D}=n \alpha t^{\frac{\alpha(1-\sigma)-\beta}{\beta}}\left(\frac{1}{1-\beta}\right)^{\frac{\beta-1}{\beta}}(\sigma-1)\left(\frac{f_{D}^{\beta} a_{D}^{\gamma} t^{\alpha(\sigma-1)}}{\varkappa^{\beta}}\right)^{\frac{1}{\beta}} \frac{k \beta}{k \beta-\gamma} a_{D}^{-\frac{\gamma}{\beta}}\left(1-\left(\left((\phi+1)^{\frac{1}{\beta}}-1\right)^{\frac{\beta}{\gamma}}\left(\frac{f_{D}}{f_{X}}\right)^{\frac{\beta}{\gamma}}\right)^{-\frac{\gamma}{\beta}+k}\right) \\
E_{D}=n \alpha t^{-1}(\sigma-1) f_{D} \frac{k}{k \beta-\gamma}\left(1-\left(\left((\phi+1)^{\frac{1}{\beta}}-1\right)^{\frac{\beta}{\gamma}}\left(\frac{f_{D}}{f_{X}}\right)^{\frac{\beta}{\gamma}}\right)^{-\frac{\gamma}{\beta}+k}\right)
\end{gathered}
$$

substitute (76) 


$$
\begin{gathered}
E_{D}=\left(\frac{\mu L_{j}(k \beta-\gamma)}{f_{D} \sigma k\left(\left((1+\phi)^{\frac{1}{\beta}}-1\right)^{\frac{k \beta}{\gamma}}\left(\frac{f_{D}}{f_{X}}\right)^{\frac{k \beta}{\gamma}-1}+1\right)}\right) \alpha t^{-1}(\sigma-1) f_{D} \frac{k}{k \beta-\gamma}\left(1-\left(\left((\phi+1)^{\frac{1}{\beta}}-1\right)^{\frac{\beta}{\gamma}}\left(\frac{f_{D}}{f_{X}}\right)^{\frac{\beta}{\gamma}}\right)^{-\frac{\gamma}{\beta}+k}\right) \\
E_{D}=\left(\frac{1-\left((1+\phi)^{\frac{1}{\beta}}-1\right)^{\frac{k \beta}{\gamma}-1}\left(\frac{f_{D}}{f_{X}}\right)^{\frac{k \beta}{\gamma}-1}}{1+\left((1+\phi)^{\frac{1}{\beta}}-1\right)^{\frac{k \beta}{\gamma}}\left(\frac{f_{D}}{f_{X}}\right)^{\frac{k \beta}{\gamma}-1}}\right) \alpha t^{-1} \frac{(\sigma-1)}{\sigma} \mu L_{j}
\end{gathered}
$$

\section{A.4.5 Exporter emissions}

Next we turn to the emissions of exporters. From the main text we have that:

$$
e^{X}=\alpha \kappa t^{\frac{\alpha-\beta}{\beta}}(1+\phi)^{-\frac{\rho \alpha}{\beta}} \bar{B}^{-\frac{\rho \alpha}{\beta}}\left(\frac{1}{1-\beta}\right)^{\frac{\rho \alpha}{\beta}} a^{\frac{1-\alpha}{\beta}} x
$$

where

$$
x=(1+\phi) \frac{p^{-\sigma} \mu L}{P^{1-\sigma}}
$$

Substituting (50) gives the exporter price

$$
p=\frac{\sigma}{\sigma-1} \kappa(1+\phi)^{-\frac{\rho \alpha}{\beta}} B^{-\frac{\rho \alpha}{\beta}}\left\{\frac{1}{1-\beta}\right\}^{\frac{\rho \alpha}{\beta}} t^{\frac{\alpha}{\beta}} a^{\frac{(1-\alpha)}{\beta}},
$$

and substituting this into (88) gives

$$
x=(1+\phi) \frac{\left(\frac{\sigma}{\sigma-1}\right)^{-\sigma} \kappa^{-\sigma} \mu L(1+\phi)^{\frac{\sigma \rho \alpha}{\beta}} B^{\frac{\sigma \rho \alpha}{\beta}}\left(\left\{\frac{1}{1-\beta}\right\}^{\frac{\rho \alpha}{\beta}} t^{\frac{\alpha}{\beta}} a^{\frac{(1-\alpha)}{\beta}}\right)^{-\sigma}}{P^{1-\sigma}}
$$

We have that $B \equiv \frac{\kappa^{1-\sigma} \sigma^{-\sigma}(\sigma-1)^{\sigma-1} \mu L_{j}}{P_{j}^{1-\sigma}}$, which implies that $\frac{(\sigma-1) B}{\kappa}=\frac{\kappa^{-\sigma} \sigma^{-\sigma}(\sigma-1)^{\sigma} \mu L_{j}}{P_{j}^{1-\sigma}}$, which we substitute into (89) to get

$$
x=\frac{(\sigma-1)}{\kappa}(1+\phi)^{1+\frac{\sigma \rho \alpha}{\beta}} B^{\frac{\sigma \rho \alpha}{\beta}+1} t^{-\frac{\sigma \alpha}{\beta}} a^{-\frac{\sigma(1-\alpha)}{\beta}}\left\{\frac{1}{1-\beta}\right\}^{-\frac{\sigma \rho \alpha}{\beta}},
$$

and this in turn into $(87)$ gives $\bar{e}^{X}$ :

$$
\bar{e}^{X}=\alpha t^{\frac{\alpha(1-\sigma)-\beta}{\beta}}\left(\frac{1}{1-\beta}\right)^{\frac{\beta-1}{\beta}} a^{-\frac{\gamma}{\beta}}(\sigma-1)(1+\phi)^{\frac{1}{\beta}} B^{\frac{1}{\beta}}
$$


$\left(\right.$ compare $\left.e^{D}=\alpha t^{\frac{\alpha(1-\sigma)-\beta}{\beta}}\left(\frac{1}{1-\beta}\right)^{\frac{\beta-1}{\beta}} a^{-\frac{\gamma}{\beta}}(\sigma-1) B^{\frac{1}{\beta}}\right)$ substitute $B=\frac{f_{D}^{\beta} a_{D}^{\gamma} t^{\alpha(\sigma-1)}}{\varkappa^{\beta}}$ gives

$$
\begin{gathered}
\bar{e}^{X}=\alpha t^{\frac{\alpha(1-\sigma)-\beta}{\beta}}\left(\frac{1}{1-\beta}\right)^{\frac{\beta-1}{\beta}} a^{-\frac{\gamma}{\beta}}(\sigma-1)(1+\phi)^{\frac{1}{\beta}}\left(\frac{f_{D}^{\beta} a_{D}^{\gamma} t^{\alpha(\sigma-1)}}{\varkappa^{\beta}}\right)^{\frac{1}{\beta}} \\
\bar{e}^{X}=\alpha t^{\frac{\alpha(1-\sigma)-\beta}{\beta}}\left(\frac{1}{1-\beta}\right)^{\frac{\beta-1}{\beta}} a^{-\frac{\gamma}{\beta}}(\sigma-1)(1+\phi)^{\frac{1}{\beta}} f_{D} \varkappa^{-1} t^{\frac{\alpha(\sigma-1)}{\beta}} a_{D}^{\frac{\gamma}{\beta}}
\end{gathered}
$$

substitute $a_{D}$ and use $\varkappa \equiv(1-\beta)^{\frac{1-\beta}{\beta}}-(1-\beta)^{\frac{1}{\beta}}$ gives

$$
e^{X}=\alpha t^{-1} \frac{1}{\beta}(\sigma-1) f_{D}(1+\phi)^{\frac{1}{\beta}}\left(\frac{f_{E}}{\left(\frac{\gamma}{k \beta-\gamma}\right) f_{D}\left(\left((\phi+1)^{\frac{1}{\beta}}-1\right)^{\frac{k \beta}{\gamma}} f_{D}^{\frac{k \beta}{\gamma}-1} f_{X}^{1-\frac{k \beta}{\gamma}}+1\right)}\right)^{\frac{\gamma}{k \beta}} a^{-\frac{\gamma}{\beta}} .
$$

Now calculate total emissions from all exporters using that

$$
E_{X}=n \int{ }_{0}^{a_{X}} e^{X} d G\left(a \mid a_{D}\right)
$$

We solve the integral and substitute in $\left(a_{X} / a_{D}\right)^{k}$ from $(58)$ :

$$
\begin{gathered}
E_{X}=n \alpha t^{\frac{\alpha(1-\sigma)-\beta}{\beta}}\left(\frac{1}{1-\beta}\right)^{\frac{\beta-1}{\beta}}(\sigma-1)(1+\phi)^{\frac{1}{\beta}}(B)^{\frac{1}{\beta}} \frac{k \beta}{k \beta-\gamma} . \\
\left(\left((\phi+1)^{\frac{1}{\beta}}-1\right)^{\frac{k \beta}{\gamma}} \frac{f_{D}^{\frac{k \beta}{\gamma}}}{f_{X}^{\frac{k \beta}{\gamma}}}\right) a_{X}^{-\frac{\gamma}{\beta}}
\end{gathered}
$$

Substitute $B=\frac{a_{X}^{(1-\alpha)(\sigma-1)} t^{\alpha(\sigma-1)} f_{X}^{\beta}}{\left((1+\phi)^{\frac{1}{\beta}}-1\right)^{\beta} \varkappa^{\beta}}$ from $(57)$ :

$$
\begin{gathered}
E_{X}=n \alpha t^{-1}\left(\frac{1}{1-\beta}\right)^{\frac{\beta-1}{\beta}}(\sigma-1)(1+\phi)^{\frac{1}{\beta}} \frac{f_{X}}{\left((1+\phi)^{\frac{1}{\beta}}-1\right) \varkappa} \frac{k \beta}{k \beta-\gamma} . \\
\left.\left((\phi+1)^{\frac{1}{\beta}}-1\right)^{\frac{k \beta}{\gamma}} \frac{f_{D}^{\frac{k \beta}{\gamma}}}{f_{X}^{\frac{k \beta}{\gamma}}}\right) \\
\varkappa=(1-\beta)^{\frac{1-\beta}{\beta}}-\{1-\beta\}^{\frac{1}{\beta}}
\end{gathered}
$$




$$
\begin{gathered}
E_{X}=n \alpha t^{-1} \frac{1}{\beta}(\sigma-1)(1+\phi)^{\frac{1}{\beta}} \frac{f_{X}}{\left((1+\phi)^{\frac{1}{\beta}}-1\right)} \frac{k \beta}{k \beta-\gamma} . \\
\left(\left((\phi+1)^{\frac{1}{\beta}}-1\right)^{\frac{k \beta}{\gamma}} \frac{f_{D}^{\frac{k \beta}{\gamma}}}{f_{X}^{\frac{k \beta}{\gamma}}}\right)
\end{gathered}
$$

then we substitute in $n$ from (76), which gives

$$
E_{X}=\frac{\mu L(k \beta-\gamma) \alpha(\sigma-1)(1+\phi)^{\frac{1}{\beta}}}{f_{D} \sigma k \beta t\left(\left((1+\phi)^{\frac{1}{\beta}}-1\right)^{\frac{k \beta}{\gamma}}\left(\frac{f_{D}}{f_{X}}\right)^{\frac{k \beta}{\gamma}-1}+1\right)} \frac{f_{X}}{\left((1+\phi)^{\frac{1}{\beta}}-1\right)} \frac{k \beta}{k \beta-\gamma}\left(\left((\phi+1)^{\frac{1}{\beta}}-1\right)^{\frac{k \beta}{\gamma}} \frac{f_{D}^{\frac{k \beta}{\gamma}}}{f_{X}^{\frac{k \beta}{\gamma}}}\right)
$$

simplification gives

$$
E_{X}=\frac{(1+\phi)^{\frac{1}{\beta}} \alpha(\sigma-1) \mu L}{\sigma t\left(\left((\phi+1)^{\frac{1}{\beta}}-1\right)+\left((1+\phi)^{\frac{1}{\beta}}-1\right)^{1-\frac{k \beta}{\gamma}}\left(\frac{f_{X}}{f D}\right)^{\frac{k \beta}{\gamma}-1}\right)}
$$

\section{A.4.6 Total emissions}

We have from (86) that:

$$
E_{D}=\left(\frac{1-\left((1+\phi)^{\frac{1}{\beta}}-1\right)^{\frac{k \beta}{\gamma}-1}\left(\frac{f_{D}}{f_{X}}\right)^{\frac{k \beta}{\gamma}-1}}{1+\left((1+\phi)^{\frac{1}{\beta}}-1\right)^{\frac{k \beta}{\gamma}}\left(\frac{f_{D}}{f_{X}}\right)^{\frac{k \beta}{\gamma}-1}}\right) \alpha t^{-1} \frac{(\sigma-1)}{\sigma} \mu L
$$

Using this and $E_{X}$ from (91) gives total emissions from country 1

$$
\begin{aligned}
E 1_{\text {tot }} & =E_{D}+E_{X}=\left(\frac{1-\left((1+\phi)^{\frac{1}{\beta}}-1\right)^{\frac{k \beta}{\gamma}-1}\left(\frac{f_{D}}{f_{X}}\right)^{\frac{k \beta}{\gamma}-1}}{1+\left((1+\phi)^{\frac{1}{\beta}}-1\right)^{\frac{k \beta}{\gamma}}\left(\frac{f_{D}}{f_{X}}\right)^{\frac{k \beta}{\gamma}-1}}\right) \alpha t^{-1} \frac{(\sigma-1)}{\sigma} \mu L \\
+ & \frac{\alpha(\sigma-1)(1+\phi)^{\frac{1}{\beta}} \mu L_{j} f_{X}\left(\left((\phi+1)^{\frac{1}{\beta}}-1\right)^{\frac{k \beta}{\gamma}-1}\left(\frac{f_{D}}{f_{X}}\right)^{\frac{k \beta}{\gamma}}\right)}{f_{D} \sigma t\left(\left((1+\phi)^{\frac{1}{\beta}}-1\right)^{\frac{k \beta}{\gamma}}\left(\frac{f_{D}}{f_{X}}\right)^{\frac{k \beta}{\gamma}-1}+1\right)}
\end{aligned}
$$

which can be simplified to be expressed by 
$E 1_{t o t}=\mu L \alpha t^{-1} \frac{(\sigma-1)}{\sigma} \frac{1+\left((1+\phi)^{\frac{1}{\beta}}-1\right)\left(\left((\phi+1)^{\frac{1}{\beta}}-1\right)^{\frac{k \beta}{\gamma}-1}\left(\frac{f_{D}}{f_{X}}\right)^{\frac{k \beta}{\gamma}-1}\right)}{\left((1+\phi)^{\frac{1}{\beta}}-1\right)^{\frac{k \beta}{\gamma}}\left(\frac{f_{D}}{f_{X}}\right)^{\frac{k \beta}{\gamma}-1}+1}=\mu L \alpha t^{-1} \frac{(\sigma-1)}{\sigma}$

World emissions $E^{W}=E 1_{t o t}+E 2_{\text {tot }}$

$E^{W}=\mu L \alpha t^{-1} \frac{(\sigma-1)}{\sigma} \frac{1+\left((1+\phi)^{\frac{1}{\beta}}-1\right)\left(\left((\phi+1)^{\frac{1}{\beta}}-1\right)^{\frac{k \beta}{\gamma}-1}\left(\frac{f_{D}}{f_{X}}\right)^{\frac{k \beta}{\gamma}-1}\right)}{\left((1+\phi)^{\frac{1}{\beta}}-1\right)^{\frac{k \beta}{\gamma}}\left(\frac{f_{D}}{f_{X}}\right)^{\frac{k \beta}{\gamma}-1}+1}=\mu\left(L+L^{*}\right) \alpha t^{-1} \frac{(\sigma-1)}{\sigma}$ 